\title{
Glutamate Corelease Promotes Growth and Survival of Midbrain Dopamine Neurons
}

\author{
Guillaume M. Fortin, ${ }^{1}$ Marie-Josée Bourque, ${ }^{1}$ Jose Alfredo Mendez, ${ }^{1}$ Damiana Leo, ${ }^{1}$ Karin Nordenankar, ${ }^{6}$ \\ Carolina Birgner, ${ }^{6}$ Emma Arvidsson, ${ }^{6}$ Vladimir V. Rymar, ${ }^{5}$ Noémie Bérubé-Carrière,${ }^{2}$ Anne-Marie Claveau, ${ }^{1}$ \\ Laurent Descarries, ${ }^{2,3,4}$ Abbas F. Sadikot, ${ }^{5}$ Åsa Wallén-Mackenzie, ${ }^{6}$ and Louis-Éric Trudeau ${ }^{1,4}$ \\ ${ }^{1}$ Department of Pharmacology, ${ }^{2}$ Department of Pathology and Cell Biology, ${ }^{3}$ Department of Physiology, and ${ }^{4}$ Groupe de Recherche sur le Système Nerveux \\ Central, Faculty of Medicine, Université de Montréal, Montréal, Québec, Canada H3C 3J7, ${ }^{5}$ Montreal Neurological Institute, Department of Neurology and \\ Neurosurgery, McGill University, Montreal, Québec, Canada H3A 2B4, and ' Unit of Developmental Genetics, Department of Neuroscience, Uppsala \\ University, S-751 24 Uppsala, Sweden
}

Recent studies have proposed that glutamate corelease by mesostriatal dopamine (DA) neurons regulates behavioral activation by psychostimulants. How and when glutamate release by DA neurons might play this role remains unclear. Considering evidence for early expression of the type 2 vesicular glutamate transporter in mesencephalic DA neurons, we hypothesized that this cophenotype is particularly important during development. Using a conditional gene knock-out approach to selectively disrupt the Vglut2 gene in mouse DA neurons, we obtained in vitro and in vivo evidence for reduced growth and survival of mesencephalic DA neurons, associated with a decrease in the density of DA innervation in the nucleus accumbens, reduced activity-dependent DA release, and impaired motor behavior. These findings provide strong evidence for a functional role of the glutamatergic cophenotype in the development of mesencephalic DA neurons, opening new perspectives into the pathophysiology of neurodegenerative disorders involving the mesostriatal DA system.

\section{Introduction}

Since their discovery (Bellocchio et al., 2000; Takamori et al., 2000; Herzog et al., 2001), the presence of one or the other of the three vesicular glutamate transporters (VGLUTs) has been demonstrated in many neuron populations of CNS and notably in dopamine (DA) neurons (El Mestikawy et al., 2011).

Patch-clamp recordings in single-neuron cultures initially demonstrated that mesencephalic DA neurons can establish glutamatergic synapses (Sulzer et al., 1998; Bourque and Trudeau,

Received April 20, 2012; revised 0ct. 10, 2012; accepted 0ct. 16, 2012

Author contributions: L.D., A.W.-M., and L.-E.T. designed research; G.M.F., M.-J.B., J.A.M., D.L., K.N., C.B., E.A., V.V.R., N.B.-C., and A.-M.C. performed research; G.M.F., M.-J.B., J.A.M., D.L., K.N., C.B., E.A., V.V.R., N.B.-C., L.D., A.F.S., and L.-E.T. analyzed data; G.M.F., L.D., A.F.S., A.W.-M., and L.-E.T. wrote the paper.

This work was funded by grants to L.-E.T from the Canadian Institutes of Health Research (CIHR; MOP-106556), the Parkinson Society of Canada and Brain Canada Foundation (Krembil Foundation), and partially supported by CIHR Grants MOP-3544 and MOP-106562 to L.D. L.-É.T. and L.D. also benefited from an infrastructure grant of the Fonds de la recherché en santé du Québec (FRSQ) to the Groupe de Recherche sur le Système Nerveux Central. G.F. received a graduate scholarship from the Parkinson Society of Canada and N.B.-C. was the recipient of a doctoral studentship from FRSQ. D.L. was supported by a postdoctoral fellowship from the Department of Foreign Affairs and International Trade of Canada, and by a postdoctoral fellowship from the FRSQ. Research in A.W.-M.'s laboratory was supported by the Swedish Research Council, the Swedish Brain Foundation, the Åhlén and Wiberg Foundations, the National Board of Health and Welfare, and Uppsala University, Sweden. The Swedish Foundation for International Cooperation in Research and Higher Education (STINT) also provided support for collaboration between L.-E.T.'s and A.W.-M.'s laboratories. A.F.S. was funded by operating grants from the CIHR and Natural Sciences and Engineering Research Council of Canada. We thank Dr. Xiaoxi Zhuang (University of Chicago) for providing the DAT-CRE mice, and Dr. Bradford Lowell (Harvard University Medical School) for providing the VGLUT2 flox/flox mice.

Correspondence should be addressed to Dr. Louis-Eric Trudeau, Department of Pharmacology, Faculty of Medicine, Université de Montréal, C.P. 6128, Succursale Centre-Ville, Montréal, Québec, H3C 3J7. E-mail: louis-eric.trudeau@umontreal.ca.

DOI:10.1523/JNEUROSCI.1939-12.2012

Copyright $\odot 2012$ the authors $\quad 0270-6474 / 12 / 3217477-15 \$ 15.00 / 0$
2000). Mesencephalic DA neurons were then found to express VGLUT2 mRNA (Dal Bo et al., 2004), and VGLUT2 mRNA and protein were visualized in subsets of these DA neurons and their axon terminals in both rats and mice (Kawano et al., 2006; Yamaguchi et al., 2007; Dal Bo et al., 2008; Descarries et al., 2008; Mendez et al., 2008; Bérubé-Carrière et al., 2009). Vglut2 expression by mesencephalic DA neurons was shown to be regulated developmentally (Dal Bo et al., 2008; Mendez et al., 2008). Moreover, VGLUT2 immunoreactivity was reported to disappear from tyrosine hydroxylase ( $\mathrm{TH})$-positive terminals of adult rat striatum (Bérubé-Carrière et al., 2009). While VGLUT2 allows DA neurons to release glutamate, it has been hypothesized that it may also facilitate the vesicular loading of DA (Hnasko et al., 2010), a concept called "vesicular synergy," first described for VGLUT3 in striatal cholinergic interneurons (Gras et al., 2008).

Little information is currently available regarding the functional significance of glutamate corelease by DA neurons of the CNS, but specific deletion of the Vglut2 gene in DA neurons of mice has been shown to decrease DA release in the nucleus accumbens (Hnasko et al., 2010) and alter psychostimulantinduced locomotor activation (Birgner et al., 2010; Hnasko et al., 2010) as well as cocaine self-administration (Alsiö et al., 2011). Whether such anomalies are due to loss of glutamate corelease and/or of vesicular synergy in the adult brain, or rather to a developmental perturbation, is presently unclear. The early expression of Vglut2 in developing brain (Herzog et al., 2001; Takamori et al., 2001) argues for a role of VGLUT2 during this period. Although not entirely conclusive, there is data to support an early expression of VGLUT2 by DA neurons (Dal Bo et al., 2008; 
Mendez et al., 2008). Evidence for regulation of DA neuron growth by glutamate (Schmitz et al., 2009) and for enhanced expression of Vglut2 in surviving DA neurons following toxininduced lesions (Dal Bo et al., 2008) also argues for a developmental and perhaps pro-survival role of VGLUT2 in DA neurons.

To test this hypothesis, we generated mice with a conditional deletion of the Vglut2 gene in DA neurons (cKO) and examined the effects of this deletion on the survival and growth of mesencephalic DA neurons in culture. We also determined the number of mesencephalic DA neurons, the density of striatal DA innervation, and DA release in the $\mathrm{CKO}$ mice, and examined the motor activity of these mice.

\section{Materials and Methods}

Animals

All procedures involving animals and their care were conducted in strict accordance with the Guide to Care and Use of Experimental Animals (second edition) of the Canadian Council on Animal Care as well as the Swedish Regulation and European Union Legislation. The experimental protocols were approved by the animal ethics committees of the Université de Montréal and by the University of Uppsala Animal Ethics Committee. Housing was at a constant temperature $\left(21^{\circ} \mathrm{C}\right)$ and humidity (60\%), under a fixed $12 \mathrm{~h}$ light/dark cycle and food and water ad libitum.

TH-green fluorescent protein mice. The characterization of VGluT2 expression in DA neurons during development was performed using the $\mathrm{TH}$ green fluorescent protein (TH-GFP) transgenic mouse line $\mathrm{TH}$ EGFP/21-31, which carries the enhanced GFP (EGFP) gene under the control of the TH promoter (Matsushita et al., 2002). The presence of GFP allowed identification and selection of DA neurons for single-cell reverse transcription (RT)-PCR experiments.

Conditional Vglut2 knock-out mice. All other experiments were performed using conditional Vglut 2 knock-out mice and control littermates. DAT-CRE transgenic mice (129/Sv/J background) (Zhuang et al., 2005) were mated with Vglut $2^{\text {flox/flox }}$ mice $(129, \mathrm{C} 57 \mathrm{Bl} / 6$ background) (Tong et al., 2007) carrying the exon 2 surrounded by loxP sites. A breeding colony was maintained by mating DAT-CRE; Vglut $2^{\text {flox/+ }}$ mice with Vglut ${ }^{\text {flox } /}$ flox mice. Twenty-five percent of the offspring from such mating were thus used as controls (i.e., DAT-CRE; Vglut $2^{\text {flox } /+}$ mice) and $25 \%$ lacked Vglut2 in DA neurons (i.e., DAT-CRE;Vglut $2^{\text {flox/flox }}$ mice). Only male littermates of such mating were used as study subjects.

\section{Tissue processing and cell culture}

P0-P2 mice were cryoanesthetized and decapitated for tissue collection. For older mice, animals were anesthetized with Halothane (SigmaAldrich) and decapitated. Freshly dissociated cells were prepared and obtained as previously described (Mendez et al., 2008). Primary cultures of mesencephalic DA neurons were also prepared according to previously described protocols (Fasano et al., 2008b). Mesencephalic cells were plated onto either microislands (microcultures) or monolayers (standard cultures) of astrocytes. The microculture system was used to isolate single neuron and perform recordings of autaptic synaptic responses. Mesencephalic microcultures were used for immunocytochemistry or electrophysiology experiments at 10 days in vitro (DIV). Cultures of fluorescence-activated cell sorting (FACS)-purified mesencephalic DA neurons from TH-GFP mice were prepared as previously described (Mendez et al., 2008). TH immunostaining revealed that $86 \%$ of the neurons in such cultures were dopaminergic (total of 3 cultures analyzed). Purified cultures were chronically treated (every $3 \mathrm{~d}$ ) with $20 \mu \mathrm{M}$ aminophosphonopentanoic acid (AP-5) (Tocris Bioscience), $10 \mu \mathrm{M}$ 6-cyano-7-nitroquinoxaline-2,3-dione (CNQX) (Sigma), or $40 \mu \mathrm{M} \mathrm{LY}$ 341945 (Ascent Scientific) until 12 DIV.

\section{Multiplex single-cell RT-PCR}

Collection of freshly dissociated GFP-positive neurons was performed as previously described (Mendez et al., 2008). For the single-cell RT-PCR experiments performed with TH-GFP mice, the cDNA produced was used for a multiplex TH and Vglut2 amplification. For the experiments performed on freshly dissociated cells from $\mathrm{P} 0-\mathrm{P} 2 \mathrm{cKO}$ mice, half of the
cDNA was used to amplify TH. The other half was used to amplify the wild-type (WT) or cKO Vglut2 allele.

Primers were designed not to interact with other primers for multiplex PCR. Primers were synthesized by AlphaDNA. Nested PCRs were performed during the second round for TH, WT Vglut2, and KO Vglut2. The identity of PCR products was confirmed by sequencing. Primers for single-cell RT-PCR in experiments on TH-GFP mice were as follows: TH $5^{\prime}$-gttctcaacctgctcttctcctt- $3^{\prime}$ and $5^{\prime}$-ggtagcaatttcctcctttgtgt- $3^{\prime}$; TH nested (374 bp) $5^{\prime}$-gtacaaaaccctcctcactgtctc- $3^{\prime}$ and $5^{\prime}$-cttgtattggaaggcaatctctg3'; WT Vglut2 5' -atctacagggtgctggagaagaa- $3^{\prime}$ and $5^{\prime}$-gatagtgctgttgttgaccatgt-3'; WT Vglut2 nested (234 bp) 5' -atctacagggtgctggagaagaa- $3^{\prime}$ and $5^{\prime}$-gatagtgctgttgttgaccatgt- $3^{\prime}$. Primers used for single-cell RT-PCR in experiments on cKO were as follows: $\mathrm{KO}$ Vglut $25^{\prime}$-aagaatggagtcggtaaaaca aag- $3^{\prime}$ and $5^{\prime}$-gtgatgatatagccccagaagaac- $3^{\prime}$; KO Vglut2 nested (WT allele: 417 bp; cKO allele: 165 bp) 5'-atccgtctttcatagccacaac- $3^{\prime}$ and $5^{\prime}$ tcagcatattgagggtagaggtg- $3^{\prime}$. Primers used for genotyping $\mathrm{cKO}$ mice were as follows: DAT-Cre $5^{\prime}$-accagccagctatcaactcg- $3^{\prime}$ and $5^{\prime}$-tta cattggtccagccacc-3'; lox-VGluT2: 5' -gtctactgtaagtgaagacac- $3^{\prime}$ and $5^{\prime}$-ctttaggctttcatccttgag- $3^{\prime}$.

\section{Electrophysiology}

Patch-clamp recordings were obtained from single DA neurons in microcultures using a Warner PC-505 patch-clamp amplifier (Warner Instruments) and PClamp 10 software (Molecular Devices). Borosilicate glass patch pipettes (3-6 M $\Omega$; World Precision Instruments) were filled with a potassium methylsulfate intrapipette solution consisting of the following (in mM): $145 \mathrm{KMeSO}_{4}, 10 \mathrm{NaCl}, 0.1 \mathrm{EGTA}, 2 \mathrm{ATP}$ (Mg salt), 0.6 GTP (Tris salt), 10 HEPES, 10 phosphocreatine (Tris salt), and $\mathrm{pH}$ 7.35 and osmolarity 295-300 mOsm. Series resistance was compensated to $\sim 75 \%$. After recordings, the DA phenotype of patched neuron was confirmed by $\mathrm{TH}$ immunocytochemistry as described below.

\section{Immunocytochemistry on cell cultures}

Standard and microcultures from cKO mice and standard FACS-purified cultures from TH-GFP mice were fixed with $4 \%$ paraformaldehyde (PFA), permeabilized, and nonspecific binding sites blocked. Primary anti-GFP (Ab290; Abcam) antibody was used at a 1:5000 dilution to amplify and visualize the GFP signal of freshly dissociated cells on fixed coverslips after collection of cells. Images of GFP immunostaining were then acquired with a Hamamatsu Orca-II digital-cooled CCD camera, and a workstation using the ImagePro Plus imaging software suite.

To identify and analyze the density and the development of DA neurons, a rabbit anti-TH antibody (Ab132;Millipore) was used at a dilution of 1:1000 in combination with a mouse anti-VGLUT2 antibody (135611; Synaptic Systems), at a dilution of 1:2000. The same rabbit anti-TH antibody (1:1000) was also used in combination with a mouse anti-Tau 1 antibody (MAB3420PS; Millipore Bioscience Research Reagents, 1:1000) to visualize DA neuron axons. To study the segregation of dopaminergic and glutamatergic terminals established by DA neurons, a chicken antiGFP (GFP-1020; Aves Laboratories) was used at a dilution 1:1000 in combination with a rabbit anti-VGLUT2 (135 402; Synaptic Systems) at a dilution of 1:4000 and a mouse anti-TH (MAB318; Millipore) at a dilution of 1:3000 or a rat anti-DAT (MAB369; Millipore) at a dilution of $1: 1000$.

\section{Immunohistochemistry}

Male P70 mice were deeply anesthetized with sodium pentobarbital (80 $\mathrm{mg} / \mathrm{kg}$, i.p.) and fixed by intracardiac perfusion of $150 \mathrm{ml}$ of $4 \%$ PFA. The brain was removed, postfixed by immersion for $24-48 \mathrm{~h}$ in the PFA solution at $4^{\circ} \mathrm{C}$, and washed in $\mathrm{PBS}(0.9 \% \mathrm{NaCl}$ in $50 \mathrm{~mm} \mathrm{~PB}, \mathrm{pH} 7.4)$. Coronal and sagittal $50 \mu \mathrm{m}$ sections were cut using a VT1000S vibrating microtome (Leica Microsystems). Coronal sections were permeabilized, nonspecific binding sites blocked and incubated overnight with a mouse anti-TH antibody (T1299; Sigma-Aldrich or MAB318; Millipore, 1:1000) or with a rat anti-DAT antibody (MAB369; Millipore, 1:1000) in combination with a rabbit anti-VGLUT2 antibody (135 402; Synaptic Systems, 1:2500); these were subsequently detected using mouse or rat Alexa Fluor 488-conjugated and rabbit Alexa Fluor 546-conjugated secondary antibodies (Invitrogen, 1:200). For the evaluation of TH activity, coronal 150 $\mu \mathrm{m}$ sections were cut using a VT1000S vibrating microtome. Coronal 
sections were permeabilized, nonspecific binding sites blocked and incubated overnight with a mouse anti-TH antibody (MAB318; Millipore, 1:1000) in combination with a rabbit anti-phospho-(Ser40) TH antibody (cat\# 2971; Cell Signaling Technology, 1:100); these were subsequently detected using mouse Alexa Fluor 488-conjugated and rabbit Alexa Fluor 546-conjugated secondary antibodies (Invitrogen, 1:200). Sagittal sections were preincubated for $1 \mathrm{~h}$ in a blocking solution containing $5 \%$ normal goat serum, $0.3 \%$ Triton $\mathrm{X}-100$, and $0.5 \%$ gelatin in PBS and incubated overnight with anti-TH antibody (1:1000) and then for $2 \mathrm{~h}$ in biotinylated goat anti-mouse (1:1000) (Jackson ImmunoResearchCedarlane) in blocking solution. After rinses in PBS $(3 \times 10 \mathrm{~min})$, they were incubated for $1 \mathrm{~h}$ in horseradish peroxidase-conjugated streptavidin (1:1000) (Jackson ImmunoResearch-Cedarlane), washed in PBS, and incubated for 2-5 min in Tris-buffered saline (TBS) containing 3,3'diaminobenzidine tetrahydrochloride (DAB; $0.05 \%)$ and hydrogen peroxide $(0.02 \%)$. The reaction was stopped by several washes in TBS followed by PBS, and the sections were mounted on microscope slides, dehydrated in ethanol, cleared in toluene, and coverslipped with DPX. They were examined and photographed with a Leitz Diaplan optical microscope coupled to a Spot RT color digital camera.

\section{Image acquisition with confocal microscopy}

All of the in vitro and in vivo imaging quantification analyses from $\mathrm{cKO}$ mice were performed on images captured using confocal microscopy. Images were acquired using an Olympus Fluoview FV1000 microscope (Olympus). Images acquired using 488 and 546 laser excitation were scanned sequentially to reduce nonspecific bleed-through signal. For the quantification of soma diameter, TH surface, and axon length, 10 cells per coverslip were randomly chosen and pictures acquired using a $40 \times$ water-immersion objective. For the Sholl analysis, 10 cells per coverslip were randomly chosen and pictures acquired using a $20 \times$ waterimmersion objective. For quantification of terminals in adult nucleus accumbens shell, core, or dorsal striatum, images were acquired using a $60 \times$ oil-immersion objective. For image acquisition in the dorsal striatum, five random fields on each side were taken from the left and the right hemisphere in each section. For acquisition in the nucleus accumbens core, five fields were selected next (ventromedial to ventrolateral) to the anterior commissure from the left and the right hemisphere in each section. For acquisition in the nucleus accumbens shell, five fields were acquired from the cone, intermediate, and ventrolateral subregions, from the left and the right hemisphere in each section. For quantification of TH actvity, images were acquired using a $40 \times$ water-immersion objective; five fields containing either SN or VTA were examined from each section.

\section{Image quantification}

All image quantification was performed using ImageJ (National Institutes of Health) software. We first applied a background correction at the same level for every image analyzed before quantification of any of the parameters described below. The ImageJ Sholl analysis plug-in was used to quantify neurite complexity: images were first thresholded at the same level in both control and cKO groups. The ImageJ NeuronJ (Meijering et al., 2004) plug-in was used to measure axon length. The soma diameter, average TH surface, Sholl analysis, and axon length values were obtained by averaging the values from 10 different DA neurons for each coverslip analyzed. At least nine coverslips from three different cultures were used for all quantifications. The quantification of dopaminergic and glutamatergic terminals in striatal sections performed by averaging five images coming from five different sections for every structure analyzed per animal. Images were thresholded at the same level for the control and cKO groups and quantification of terminals was performed by selecting objects with a surface area between 0.28 and $5.75 \mu \mathrm{m}^{2}$, as previously described (Fasano et al., 2010). TH and VGLUT2 colocalization analysis on slices was performed by measuring the Pearson coefficient using the ImageJ Manders coefficient (Manders et al., 1993) plug-in.

\section{Unbiased stereological analysis}

Unbiased estimates of the number of midbrain DA neurons were obtained using the optical fractionator method as previously described (van den Munckhof et al., 2003). The rostrocaudal extent of the midbrain was examined in TH-immunostained $40-\mu \mathrm{m}$-thick coronal serial sections from male $\mathrm{P} 90 \mathrm{cKO}$ and control mice, with the observer blind to genotype. TH-immunoreactive neurons were counted in every fourth section at $100 \times$ magnification using a $60 \times 60 \mu \mathrm{m}^{2}$ counting frame. Sections counted corresponded to levels $-2.54,-2.80,-3.08,-3.40,-3.64$, -3.88 , and $-4.16 \mathrm{~mm}$ ( $240 \mu \mathrm{m}$ interval), with respect to bregma (Paxinos and Franklin, 2008). A $10 \mu \mathrm{m}$ optical dissector was used with $2 \mu \mathrm{m}$ guard zones, and counting sites were located at $150 \mu \mathrm{m}$ intervals after a random start. Mesencephalic DA nuclei, including ventral tegmental area (VTA), substantia nigra pars compacta (SNc), substantia nigra pars reticulata $(\mathrm{SNr})$, and retrorubral field (RRF) were examined. Stereological estimates of the total number of TH-immunoreactive neurons within each nucleus were obtained.

\section{Fast scan cyclic voltammetry}

One-month-old male mice were anesthetized with halothane (SigmaAldrich), decapitated, and the brain was quickly removed. Coronal slices (300 $\mu \mathrm{m})$ containing the striatum were cut with a VT1000S vibrating microtome (Leica) in ice-cold artificial cerebrospinal fluid (aCSF) containing the following (in mM): $125 \mathrm{NaCl}, 26 \mathrm{NaHCO}_{3}, 2.5 \mathrm{KCl}, 2.4 \mathrm{CaCl}_{2}$, $1.3 \mathrm{MgSO}_{4}, 0.3 \mathrm{KH}_{2} \mathrm{PO}_{4}$, and 10 D-glucose saturated with $95 / 5 \% \mathrm{O}_{2} /$ $\mathrm{CO}_{2}$. After $1 \mathrm{~h}$ of recovery at room temperature, slices were put in a recording chamber and perfused with aCSF at $1 \mathrm{ml} / \mathrm{min}\left(32^{\circ} \mathrm{C} \pm 0.5\right)$. Experimental recording started $20 \mathrm{~min}$ after transfer to the slice chamber. Carbon-fiber electrodes $(5 \mu \mathrm{m})$ were prepared as described previously (Kawagoe et al., 1993). The electrode tips were placed $\sim 100 \mathrm{~nm}$ below the slice surface and the potential was linearly scanned from $-400 \mathrm{mV}$ to $+1000 \mathrm{mV}$ at $300 \mathrm{~V} / \mathrm{s}$ every $100 \mathrm{~ms}$ using an Axopatch 200B amplifier (Molecular Devices). Single ( $400 \mu \mathrm{A}, 1 \mathrm{~ms}$ ), and train ( $10 \mathrm{~Hz}, 20$ pulses) pulses were computer generated and delivered by an S-900 stimulator (Dagan) through a bipolar electrode (Plastics One) placed on the surface of the slice. Slices were stimulated every $2 \mathrm{~min}$.

\section{Animal housing for behavioral studies}

Male mice, 3 to 5 months old, were housed in standard macrolon cages $(59 \times 38 \times 20 \mathrm{~cm})$ with aspen wood bedding (Scanbur AB Sollentuna) and a wooden house. The temperature was $21-22^{\circ} \mathrm{C}$, the humidity $45-$ $55 \%$, and a $12 \mathrm{~h} \mathrm{light/dark} \mathrm{cycle} \mathrm{was} \mathrm{used,} \mathrm{lights} \mathrm{on} \mathrm{at} \mathrm{7:00.} \mathrm{The} \mathrm{animals}$ had water and food ad libitum (R36, Labfor, Lactamin). In all experiments, littermates were used to ensure that group differences were only dependent on genotype. The experimenter/observer was blind to the genotype of the mice throughout the study. Behavioral tests were performed on 12 male cKO animals and 7 male control mice. The animals were tested between 8:00 A.M. and 18:00 P.M.

\section{Rotarod}

The accelerating rotarod task was used to assess motor coordination and balance. The apparatus consisted of five rotating rods separated by walls and elevated $30 \mathrm{~cm}$ from the ground. The mouse was placed facing forward on the rod and the speed of rotation was gradually increased from 0 to $45 \mathrm{rpm}$ in $1 \mathrm{~min}$. The mouse had to continuously walk forward to stay on the cylinder. The rotations were counted and the trial was stopped upon falling from the rod. Duration, speed, and number of rotations were compared. Three trials per day were performed and averaged.

\section{Forced swim test}

The forced swim test was used to assess depressive behavior (Porsolt et al., 1977). The mice were subjected to two trials where they were placed in a Plexiglas cylinder filled with $30 \mathrm{~cm}$ deep water $\left(25^{\circ} \mathrm{C}\right)$. Each animal was videotaped for $6 \mathrm{~min}$ and thereafter scored using AniTracker software for the time spent swimming and latency to first become still.

\section{Spontaneous and psychostimulant-induced motor activity in a novel environment}

To evaluate spontaneous motor behavior in a novel environment, the mice were placed in cages designed for activity monitoring (Locobox; Kungsbacka Reglerteknik AB) containing a plastic box $(55 \times 55 \times 22$ $\mathrm{cm}$ ) inside a ventilated and illuminated (10 lux) cabinet for $40 \mathrm{~min}$. Mice were then administered saline and three different doses of amphetamine $(0.75 \mathrm{mg} / \mathrm{kg}, 1.5 \mathrm{mg} / \mathrm{kg}$, and $3.0 \mathrm{mg} / \mathrm{kg}$, respectively) through intraperi- 
toneal injection in a randomized order with a minimum of 1 week between doses. Motor behavior was monitored for $90 \mathrm{~min}$ following injection. Preceding all injections, animals were allowed to acclimatize to the environment and basal motor activity was recorded. The mice were returned to their home cages directly after activity monitoring.

Five weeks after the amphetamine study was finished, the mice were analyzed for cocaine-induced response in the same activity-monitoring setup as for amphetamine-induced response. In this study, the same mice were used, except one cKO male mouse that had died. First, the mice were injected intraperitoneally with saline and activity was recorded. After a 1 week rest, they were treated with $10 \mathrm{mg} / \mathrm{kg}$ cocaine and activity was recorded again.

\section{Statistics}

Data are represented throughout as mean \pm SEM. Statistically significant differences were analyzed using Student's $t$ test, one-way repeatedmeasures ANOVA, two-way ANOVA, or the Mann-Whitney rank sum test, as appropriate. One animal was considered as an outlier (>2 SD) and was rejected from the final analysis of the stereological counting experiment.

\section{Results}

\section{Early developmental expression of Vglut 2 in DA neurons}

To substantiate previous findings showing that Vglut2 is expressed early in developing DA neurons (Dal Bo et al., 2004, 2008), we profiled DA neurons, using single-cell RT-PCR, to detect the presence of Vglut2 mRNA, as well as mRNA for the DA neuron marker Th, at different prenatal (E14, E16, E18) and postnatal (P0-P2, P14, P35, P70) time points. Neurons were freshly dissociated from the ventral mesencephalon of TH-GFP transgenic mice expressing the GFP gene under control of the $\mathrm{TH}$ promoter. Only GFP-expressing neurons were collected (Fig. $1 A, B)$.

The proportion of TH-positive neurons expressing Vglut2 mRNA (Fig. 1C) was 7\% (1/15) at E14, 47\% at E16 (9/19), 33\% $(9 / 27)$ at $\mathrm{E} 18,22 \%(8 / 37)$ at $\mathrm{P} 0-\mathrm{P} 2,14 \%(4 / 28)$ at $\mathrm{P} 14,30 \%$ $(10 / 33)$ at $\mathrm{P} 35$, and $47 \%(7 / 15)$ at P70 (Fig. 1D). To extend these data, obtained from whole ventral mesencephalon, we also examined separately substantia nigra (SN) and VTA DA neurons obtained from P0-P2 and P70 mice (Fig. 1E). The proportion of Th/Vglut2 neurons was almost threefold higher in the VTA (P0P2: 36\%, 5/14; P70: 78\%, 14/18) than in the SN (P0-P2: 13\%, 3/23; P70: 25\%, 2/8). mRNA for the DA transporter (DAT), another marker of DA neurons, was detected in a majority of DA neurons at both prenatal $(83 \%$ at E16) and postnatal $(89 \%$ at P35) ages (Fig. $1 F, G$ ). Finally, in standard primary mesencephalic cultures prepared from P0-P2 TH-GFP pups, single-cell RT-PCR showed that $38 \%(8 / 21)$ of $\mathrm{TH}+$ cells contained VGLUT2 mRNA at $1 \mathrm{DIV}$, suggesting the existence of a certain amount of upregulation of the Vglut2 gene in culture, as previously described (Mendez et al., 2008). Together, these results indicate that Vglut2 is expressed early in developing VTA and SN DA neurons, in keeping with a role early in development.

\section{Absence of Vglut2 mRNA, VGLUT2 protein, and glutamate release in DA neurons from cKO mice}

We used a cKO approach to selectively disrupt the Vglut 2 gene in DAT-expressing DA neurons (Fig. 2). The cKO mice were generated by crossing DAT-Cre mice with Vglut2 floxed mice (see Materials and Methods). The effectiveness of the strategy was evaluated by single-cell RT-PCR on freshly dissociated cells from the mesencephalon of $\mathrm{P} 0-\mathrm{P} 2$ pups. We found that in cKO pups, all $\mathrm{TH}$-positive DA neurons expressed the Vglut2 $\mathrm{KO}$ allele, but not the Vglut2 WT allele (Fig. $2 A, B$ ). Likewise, every TH-positive DA neuron collected from control littermates expressed the WT
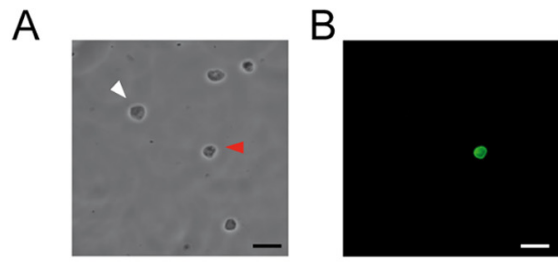

C

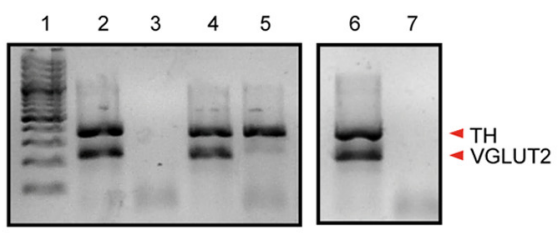

D

\begin{tabular}{|c|c|}
\hline TH-GFP mice & $\begin{array}{c}\text { \% TH+ cells } \\
\text { expressing VGLUT2 }\end{array}$ \\
\hline \hline E14 & $7 \%(1 / 15)$ \\
\hline \hline E16 & $47 \%(9 / 19)$ \\
\hline E18 & $33 \%(9 / 27)$ \\
\hline P0-P2 & $22 \%(8 / 37)$ \\
\hline \hline P14 & $14 \%(4 / 28)$ \\
\hline \hline P35 & $30 \%(10 / 33)$ \\
\hline \hline P70 & $47 \%(7 / 15)$ \\
\hline
\end{tabular}

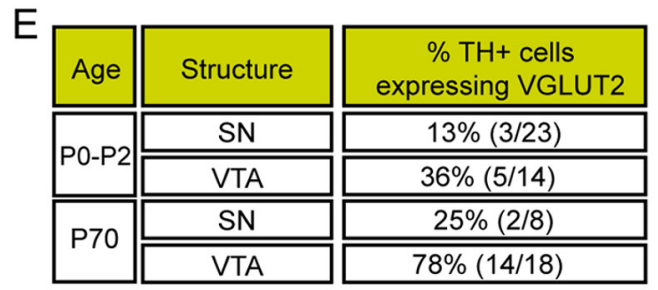

F

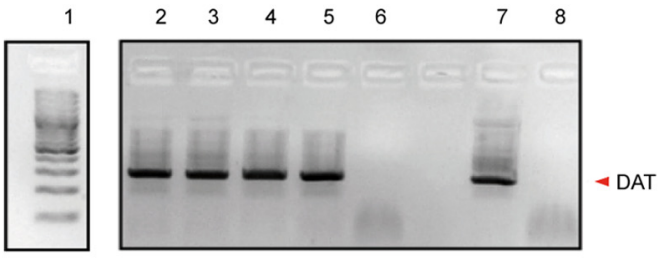

$G$

\begin{tabular}{|c|c|}
\hline TH-GFP mice & $\begin{array}{c}\% \text { TH+ VGLUT2+ cells } \\
\text { expressing DAT }\end{array}$ \\
\hline \hline E16 & $83 \%(5 / 6)$ \\
\hline \hline P35 & $89 \%(8 / 9)$ \\
\hline
\end{tabular}

Figure 1. DA neurons express Vglut2 early in development. $\boldsymbol{A}$, Phase-contrast and ( $\boldsymbol{B})$ epifluorescence view of a $40 \times$ field containing five dissociated cells obtained from the mesencephalon of an E18 TH-GFP mouse embryo. Only the GFP + cells (red arrows) were individually collected for RT-PCR. Scale bar, $25 \mu \mathrm{m}$. C, Single-cell RT-PCR from freshly dissociated E16 TH-GFP cells. In this example (wells 2-5), two of the three TH-positive neurons collected expressed Vglut2 mRNA. Well 1, DNA ladder; well 6, whole mesencephalon RNA; well 7, water control. $\boldsymbol{D}$, Table summarizing the results of single-cell RT-PCR experiments performed with mice aged E14 to P70. $\boldsymbol{E}$, Table summarizing the results of single-cell RT-PCR experiments comparing the VTA and SN of a P0-P2 and P70 mice. $\boldsymbol{F}, \boldsymbol{G}$, Dat mRNA is expressed in most double phenotype neurons. $\boldsymbol{F}$, Results of a single-cell RT-PCR experiment performed with freshly dissociated P35 TH-GFP cells. In this example (wells 2-6), four of the five double phenotype neurons (TH and VGLUT2-positive neurons) collected expressed Dat mRNA. Well 1, DNA ladder; well 7, whole mesencephalon RNA; well 8, water control. G, Table summarizing the results of single-cell RT-PCR experiments performed with mice aged E16 and P35. 
A
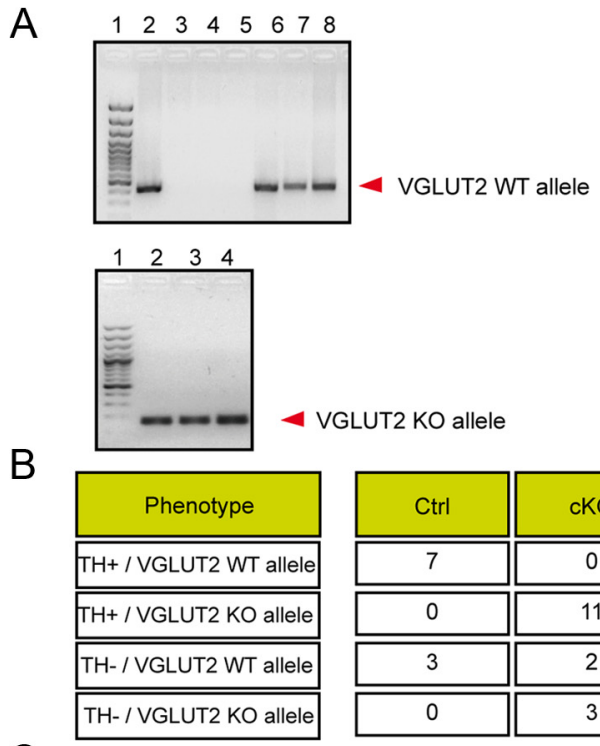

C
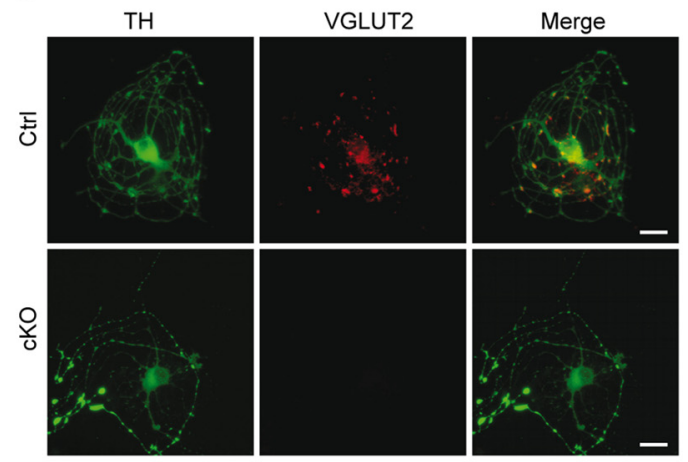

D
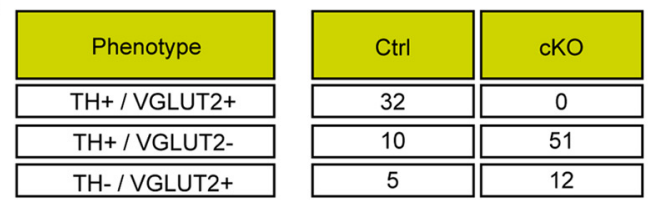

E

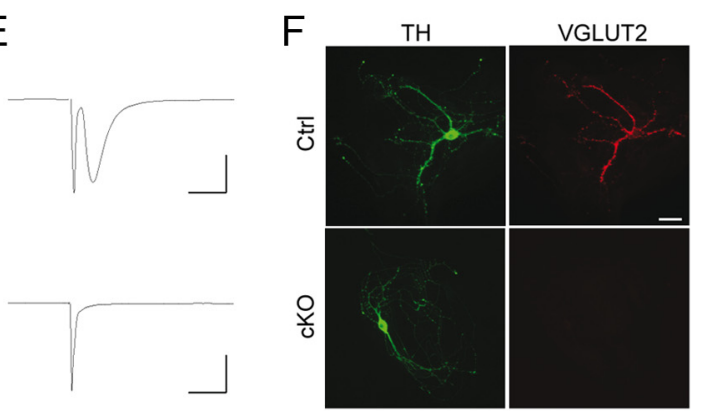

Figure 2. Absence of VGLUT2 prevents glutamate release from cultured DA neurons obtained from conditional KO mice. A, Gel image showing a single-cell RT-PCR experiment performed with freshly dissociated cells from the mesencephalon of $P 0-P 2$ control and $\mathrm{KKO}$ mice. Th and Vglut2 allele mRNA were amplified. Note that the size of the Vglut2 WT allele was $417 \mathrm{bp}$, whereas the K0 allele was $165 \mathrm{bp}$. Top, $\mathrm{TH}-$ (wells 2-5) or TH + (wells 6-8), freshly dissociated cells from the mesencephalon of P0 -P2 control pups were tested to detect Vglut2; three of the three DA neurons expressed the WT Vglut2 allele. Well 1, DNA ladder. Bottom, TH - (well 2) or $\mathrm{TH}+$ (wells $3-4$ ) freshly dissociated cells from the mesencephalon of $\mathrm{P} 0-\mathrm{P} 2$ cKO pups were tested to detect Vglut2; two of the two DA neurons expressed the KO Vglut2 allele. Well 1, DNA ladder. $\boldsymbol{B}$, Summary data showing that the WT Vglut2 allele was detected in all mesencephalic DA neurons collected from control mice, and the $\mathrm{KO}$ allele was detected in all TH-positive DA neurons collected from cKO mice. C, Immunofluorescence images of a TH and VGLUT2
Vglut2 allele (Fig. 2A,B). We also found a small contingent of $\mathrm{TH}$-negative neurons collected from cKO tissue that expressed the Vglut2 $\mathrm{KO}$ allele (Fig. $2 B$ ), thus suggesting that the DAT promoter was active temporarily during development in a subset of mesencephalic glutamatergic neurons.

To further confirm the success and selectivity of the cKO strategy, we examined VGLUT2 protein expression in singleneuron cultures prepared from the ventral mesencephalon of cKO mice and control littermates (Fig. 2C,D). Mesencephalic DA neurons cultured on microislands can form autapses and express high levels of VGLUT2 protein (Dal Bo et al., 2004; Mendez et al., 2008), thus allowing the recording of robust autaptic currents mediated by glutamate. Confirming previous findings (Dal Bo et al., 2004; Mendez et al., 2008), we found that the majority of isolated TH-positive DA neurons in control cultures were immunopositive for VGLUT2 (32/42) (Fig. 2C,D). We also found five control TH-negative neurons expressing VGLUT2, consistent with the presence of glutamatergic neurons in the ventral mesencephalon (Yamaguchi et al., 2007; Dobi et al., 2010). In cultures prepared from cKO mice, there were no DA neurons positive for VGLUT2 (0/51) (Fig. 2C,D). In cKO cultures, we also found $12 \mathrm{TH}$-negative neurons positive for VGLUT2, thus demonstrating that the KO was selective for DA neurons and did not lead to loss of VGLUT2 in all mesencephalic glutamate neurons.

Patch-clamp recordings of autaptic synaptic currents from isolated DA neurons were used to evaluate whether Vglut2 gene deletion leads to the predicted loss of the capacity for glutamate release by DA neurons. In keeping with previous findings (Sulzer et al., 1998; Bourque and Trudeau, 2000), autaptic glutamate-mediated EPSCs were detected in 7 of 13 isolated TH-positive neurons in control cultures (Fig. 2E). In contrast, no EPSCs were observed in 18 isolated TH-positive DA neurons recorded from cKO cultures (Fig. 2E). Postrecording immunocytochemistry confirmed that EPSCs were recorded in DA neurons containing VGLUT2, while this protein was undetectable in DA neurons from cKO cultures (Fig. $2 F)$. Together, these results confirm the selective and complete deletion of the Vglut2 gene from DA neurons and show that this manipulation abrogates the ability of DA neurons to release glutamate.

\section{Deletion of Vglut 2 causes DA neuron loss in culture}

To evaluate the possibility of a developmental role of VGLUT2 in DA neurons and to test the hypothesis of a contribution of glutamate cotransmission to cell survival, we first counted the number and proportion of DA neurons in primary mesencephalic cultures prepared from Ctrl and cKO P0-P2 mice (Fig. 3A). Immunocytochemistry experiments revealed that the number of TH-positive neurons normalized to the total population of neurons present on each coverslip was significantly decreased in the cKO cultures compared with $\mathrm{Ctrl}$ at all time points examined: 1 DIV, $23 \%$ decrease $(77.1 \pm 6.0 \%$ of control); 5 DIV, $29 \%$ decrease (71.2 $\pm 6.3 \%$ of control); and

$\leftarrow$

immunolabeling experiment performed in single-neuron microcultures. VGLUT2 was undetectable in cultured DA neurons from cKO mice. Scale bar, $25 \mu \mathrm{m}$. D, Summary data of the immunolabeling experiments shown in $\boldsymbol{C}$. $\boldsymbol{E}$, Top, Patch-clamp recording showing a sodium current followed by a large glutamate-mediated EPSC recorded in a control DA neuron. Bottom, EPSCS were undetectable in DA neurons recorded from cKO cultures. Calibration: $5 \mathrm{nA}, 10 \mathrm{~ms}$. $\boldsymbol{F}$, Postrecording TH/VGLUT2 immunocytochemistry confirmed the absence of VGLUT2 protein from cKO DA neurons. Scale bar, $20 \mu \mathrm{m}$. 
A
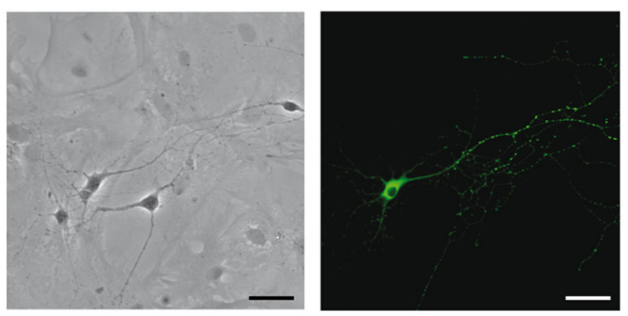

B

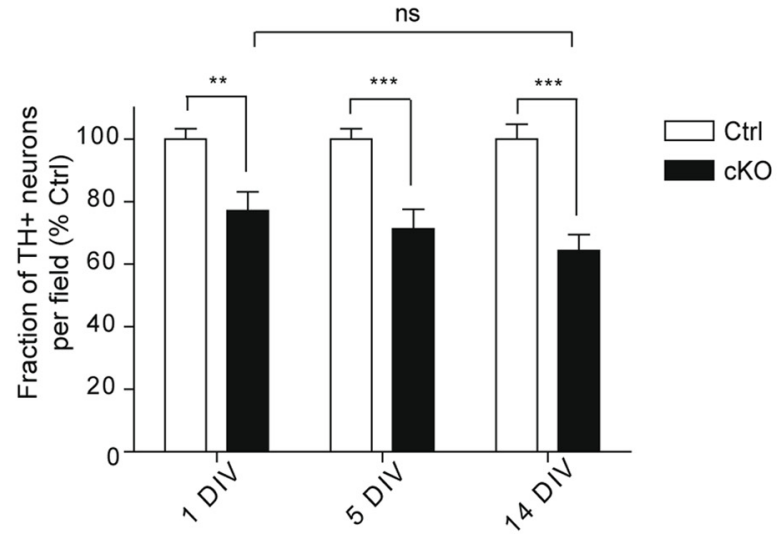

C
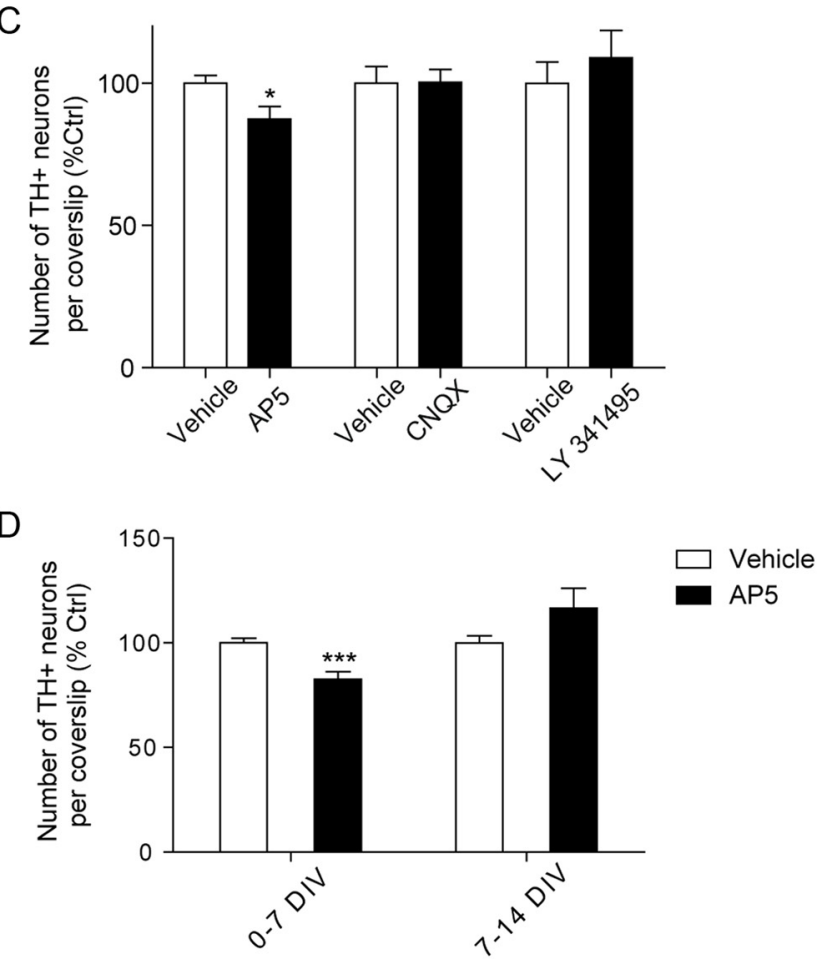

Figure 3. Loss of VGLUT2 reduces the number of DA neurons in culture. $\boldsymbol{A}$, Phase contrast (left) and immunofluorescence (right) micrographs prepared from control mesencephalic neurons after 5 DIV. One of the neurons is TH positive (green). Scale bar, $40 \mu \mathrm{m}$. B, In vitro counts of TH-positive mesencephalic neurons at 1, 5, and 14 DIV. The TH-positive neuron counts are normalized to the total number of neurons per field. Compared with control cultures, there was a significant decrease in the proportion of TH-positive neurons per coverslip in cKO cultures at 1 DIV ( ${ }^{* *} p<0.01$; Student's $t$ test, $\left.n=9\right)$, 5 DIV ( ${ }^{* * *} p<0.001$; Student's $t$ test, $\left.n=8\right)$, and 14 DIV ( ${ }^{* * *} p<0.001$; Student's $t$ test, $\left.n=8\right)$. $n$ represents the number of coverslips analyzed in three different cultures. $\boldsymbol{C}$, In vitro counts of TH-positive DA neurons after 12 DIV. DA neurons were FACS-purified from the mesencephalon of P0 -P2 TH-GFP mice. Compared with control (water), there was a significant decrease in the number of TH-positive neurons per coverslip in cultures treated chronically with $20 \mu \mathrm{m} \mathrm{AP-5}\left({ }^{*} p<0.05\right.$; Student's $t$ test, $\left.n=15\right)$. Compared with control (dimethylsulfoxide), there was no difference in the number of $\mathrm{TH}$-positive neurons
14 DIV, 36\% decrease $(64.3 \pm 5.1 \%$ of control). The average data, normalized to the control group of each experiment, is shown in Fig. 3B. There was no significant difference in the survival of DA neurons in cKO cultures from 1 to 14 DIV (Fig. $3 B)$.

\section{NMDA receptors contribute to the survival of DA neurons in purified DA neurons culture}

Considering that glutamate release from DA neurons has been shown to activate ionotropic AMPA/kainate and NMDA receptors (Stuber et al., 2010; Tecuapetla et al., 2010) and that NMDA receptors are also present on the growth cone of developing DA neurons (Schmitz et al., 2009), we next evaluated which class of glutamate receptors contributes to survival. Purified DA neuron cultures were prepared by automated cell sorting from $\mathrm{P} 0-\mathrm{P} 2$ TH-GFP mice to exclude indirect drug effects through an action on non-DA neurons. DA neurons were treated chronically for $12 \mathrm{~d}$ with either AMPA/kainate (CNQX), NMDA (AP-5), or mGluR (LY 341495) receptor antagonists. The number of THpositive neurons was significantly decreased in AP-5-treated cultures $(87.38 \pm 4.38 \%$ of control, $p=0.02)$ (Fig. $3 C$ ). However, no difference was observed in cultures treated with CNQX or LY 341495 (Fig. 3C). If glutamate release in developing DA neuron growth cones leads to a pro-survival autocrine-like activation of NMDA receptors (Schmitz et al., 2009), we reasoned that blocking these receptors at an early stage of development should have a greater effect on survival than at a later stage. To test this hypothesis, we treated purified DA neuron cultures with AP-5 from 0 to 7 DIV or from 7 to 14 DIV. We observed decreased survival of $\mathrm{TH}+$ neurons treated with AP-5 between 0 and 7 DIV (82.54 \pm $3.64 \%$ of control, $p=0.0006)$, but no difference when treated from 7 to 14 DIV (115.1 $\pm 8.99 \%$ of control, $p=0.14$; Fig. $3 D)$.

\section{Deletion of Vglut2 impairs DA neurons growth in vitro}

In keeping with a developmental role, it has recently been proposed that glutamate regulates axonal growth in cultured DA neurons (Schmitz et al., 2009). To test the hypothesis that glutamate release by DA neurons contributes to the growth of these cells, we examined DA neurons in culture after 1 DIV to quantify soma size, neurite complexity, and axonal length (Fig. $4 A, B$ ). The soma diameter of TH-positive neurons was found to be modestly $(6.2 \%)$ but significantly reduced in cultures prepared from $\mathrm{cKO}$ mice compared with control (93.8 \pm $1.6 \%$ of control, $p=0.03$ ) (Fig. $4 C$ ). We also examined the total surface of $\mathrm{TH}$-immunoreactive neurites to provide a global index of cell size, including axons and dendrites. This surface was $17.9 \%$ smaller in cKO cultures $(82.1 \pm 4.4 \%$ of control, $p=0.001$ ) compared with control DA neurons (Fig. $4 D)$. Sholl analysis was also used to evaluate branching complexity. The number of intersections crossing analysis circles was significantly smaller $(p=0.05)$ in $\mathrm{CKO}$ than in control DA neurons (Fig. 4E), reflecting reduced complexity. Axon growth was finally quantified by measuring the length of the longest neurite, confirmed in initial experiments to be immunopositive for Taul (Fig. $4 F$ ). We observed that at 1 DIV, axon

$\leftarrow$

per coverslip in cultures treated chronically with $10 \mu \mathrm{M} C N Q X(n=9)$ or with $40 \mu \mathrm{MLY} 341495$ $(n=11)$. D, In vitro counts of TH-positive DA neurons from FACS-purified DA neurons cultures treated chronically with $20 \mu \mathrm{M} \mathrm{AP-5}$ from either 0 to $7 \mathrm{DIV}$ or from 7 to $14 \mathrm{DIV}$. ${ }^{* * *} p<0.001$; Student's $t$ test, $n=14$ ). $n$ represents the number of coverslips analyzed in at least three different cultures. 
A

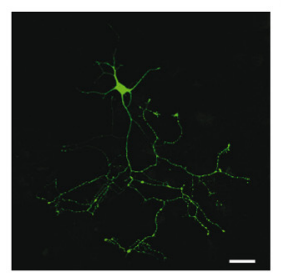

E

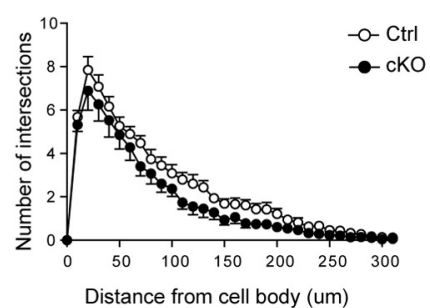

B

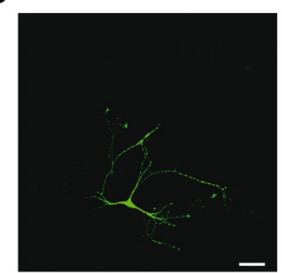

F

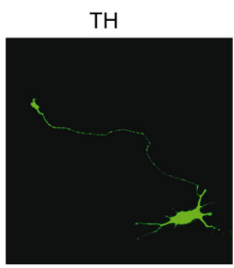

C

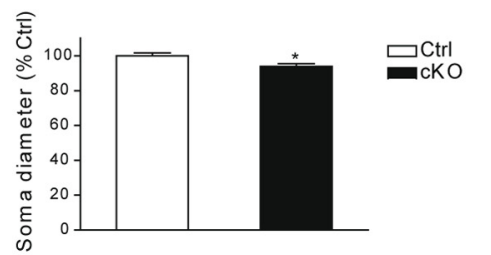

D

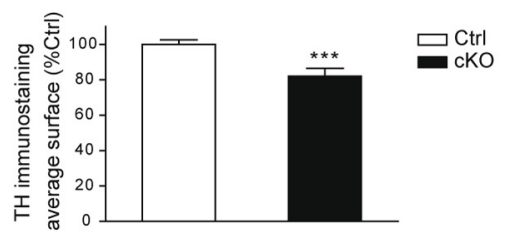

G
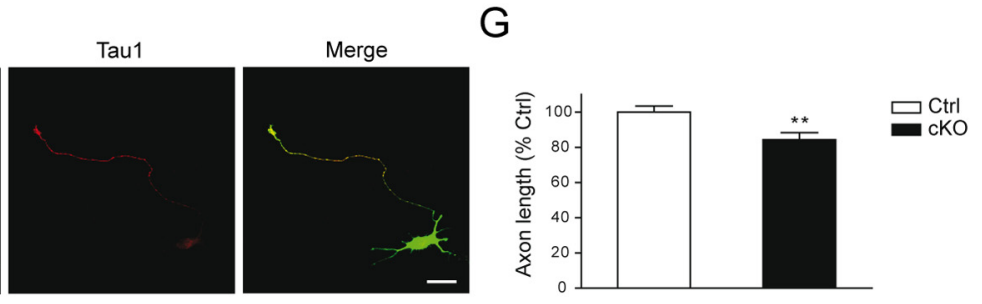

Figure 4. Deletion of Vglut2 impairs DA neuron development. $\boldsymbol{A}$, Cultured mesencephalic DA neurons from control $(\boldsymbol{A})$ or CKO P0-P2 mice (B) were identified by TH immunostaining (green) before quantitative image analysis. Scale bars: $40 \mu \mathrm{m}$. C, cKO DA neurons are significant smaller in soma diameter ( ${ }^{*} p<0.05$; Student's $t$ test, $n=9$ for both genotypes). $\boldsymbol{D}$, cKO DA neurons also have a smaller TH-positive surface area, reflecting reduced neurite development $\left({ }^{* * *} p<0.001\right.$; Student's $t$ test, $n=21$ for control, $n=20$ for cKO). $\boldsymbol{E}$, Average results from a Scholl analysis of neurite complexity. (KO DA neurons show reduced neurite complexity ( ${ }^{*} p<0.05$; two-way ANOVA (genotype by distance), $n=9$ for both genotypes, no interaction). $F$, Micrographs from a control DA neuron at 1 DIV. Axon length (green) was evaluated by measuring the length of the longest neurite where an axonal growth cone was apparent. This longest neurite was also generally Tau1 immunopositive (red). Scale bar, $25 \mu \mathrm{m}$. G, Bar graph showing that axon length was significantly shorter in cKO DA neurons (** $p<0.01 ;$ Student's $t$ test, $n=21$ for control, $n=20$ for cK0). $n$ represents the number of coverslips per genotype analyzed in a minimum of three different cultures; 10 neurons were analyzed in each coverslip.

A
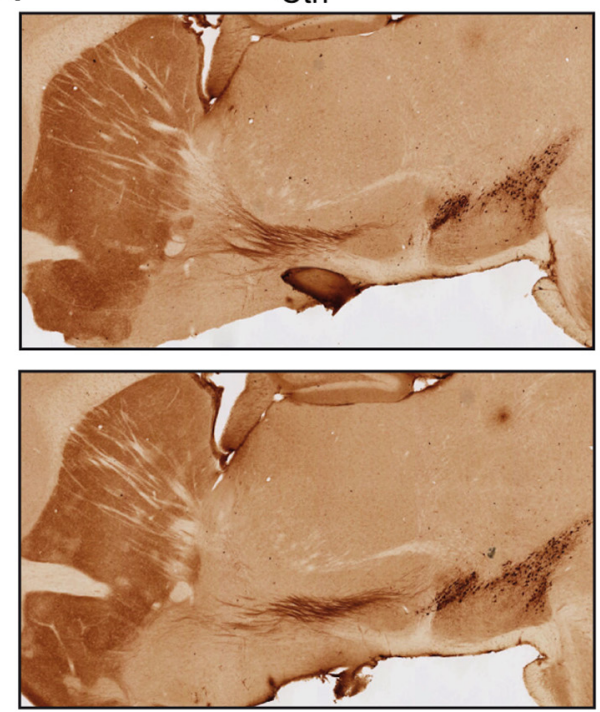

$B$
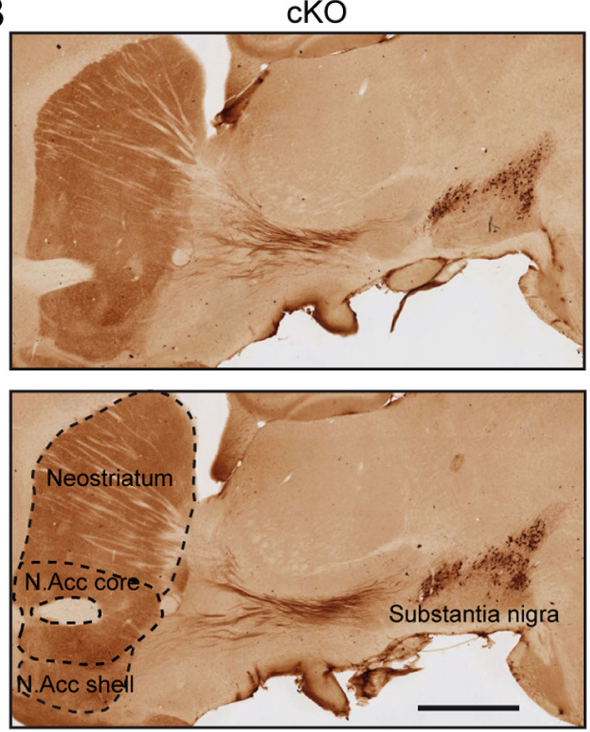

Figure 5. The general organization of dopaminergic projections is normal in cK0 mice. Micrographs showing TH immunostaining in $50 \mu \mathrm{m}$ sagittal brain sections prepared from either $(\boldsymbol{A})$ control or (B) cK0 P70 mice. Scale bar, $1 \mathrm{~mm}$. N. Acc, nucleus accumbens.

length was $15.7 \%$ shorter in cKO DA neurons $(84.3 \pm 4.0 \%$ of control, $p=0.005$ ) than in control DA neurons (Fig. $4 G$ ). Together, these results show that loss of VGLUT2 and the capacity for glutamate release impairs the morphological development of DA neurons.

\section{Deletion of Vglut 2 compromises the development of the mesostriatal DA system in vivo}

To determine whether the growth impairment observed in vitro would result in some disorganization of the mesostriatal DA projection, we examined sagittal brain sections from adult cKO and control mice after $\mathrm{TH}$ immunolabeling with the immunoperoxidase-DAB technique. No overt changes in the configuration of the median forebrain bundle DA pathway were observed (Fig. 5).

The reduced number of TH-positive neurons observed as soon as $1 \mathrm{DIV}$ in mesencephalic cultures prepared from $\mathrm{cKO}$ mice suggests the possibility that in vivo as well, independently of cell culture, there is a reduced number of DA neurons. Therefore, we next used unbiased stereological counting to quantify the number of DA neurons in mesencephalic brain sections prepared from both control and cKO P90 mice. The total number of THpositive neurons was found to be decreased by $19.7 \%$ in $\mathrm{cKO}$ tissue compared with control littermate tissue (control = $12185 \pm 413, \mathrm{cKO}=9784 \pm 302, p=0.0006)$. Analysis of different mesencephalic substructures revealed that the number of 
A

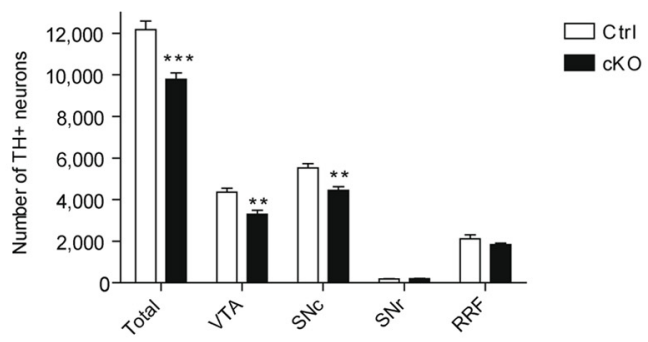

B
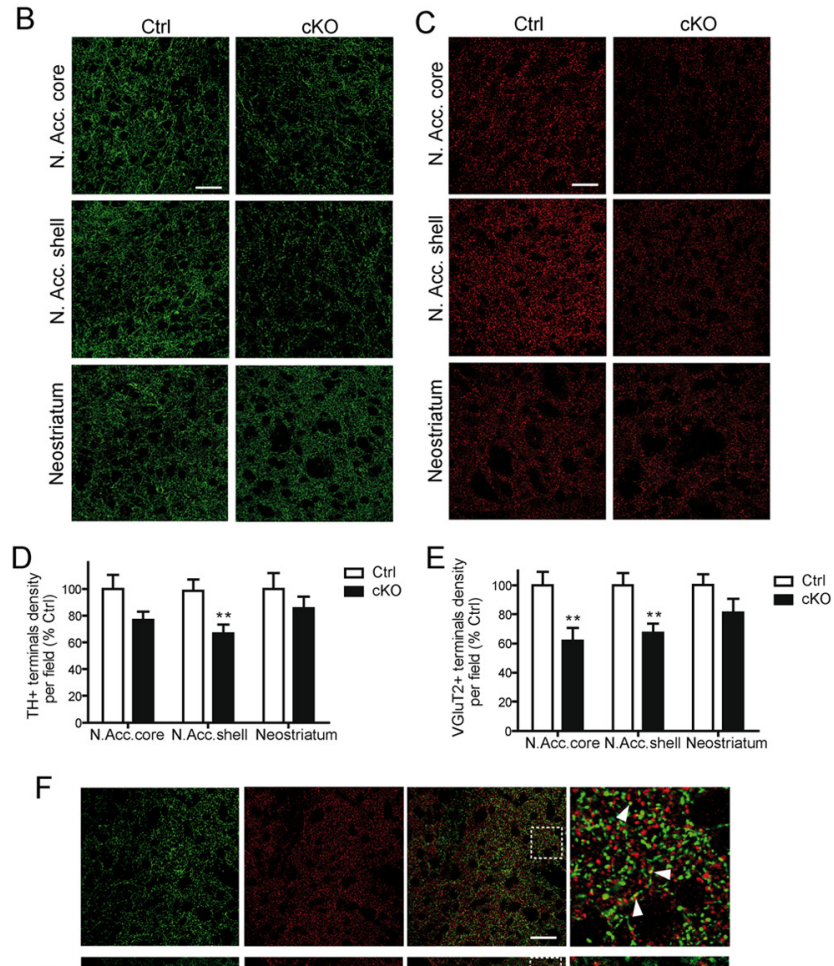

G
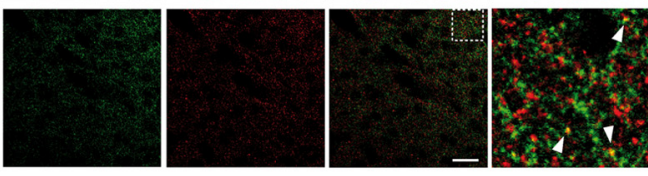

$\mathrm{H}$

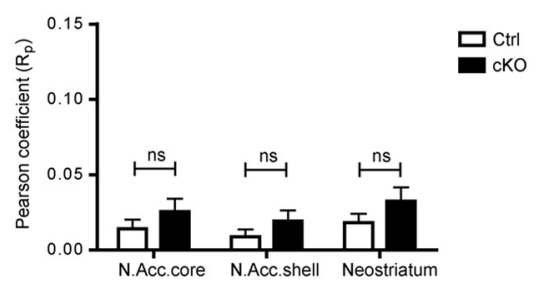

Figure 6. Reduced number of mesencephalic DA neurons and decreased density of dopaminergic and glutamatergic innervation in the nucleus accumbens (N. Acc) of conditional Vglut2 $\mathrm{KO}$ mice. $\boldsymbol{A}$, Extrapolation of the total number of $\mathrm{TH}$-positive neurons in adult cKO and littermate control P90 mice by unbiased stereological counting. Compared with littermate control mice (Ctrl), there was a smaller number of TH-positive neurons in the VTA $\left({ }^{* *} p<0.01\right.$; Student's $t$ test, $n=6$ for control, $n=7$ for cK0), SNc ( ${ }^{* *} p<0.01$; Student's $t$ test, $n=6$ for control, $n=$ 7 for $\mathrm{CKO}$ ), and whole SN ( ${ }^{* * *} p<0.001$; Student's t test, $n=6$ for control, $n=7$ for $c K 0$ ) of $c$ KO mice (KO). $n$ represents the number of animals. Confocal images of $(\boldsymbol{B})$ TH (green) and (C) VGLUT2 (red) immunoreactivity examined in the nucleus accumbens core, shell, and neostriatum of control and P70 CKO mice. Scale bars: $40 \mu \mathrm{m}$. D, Summary data showing the existence of a significant reduction in the number of $\mathrm{TH}$-positive varicosities in the nucleus accumbens shell of cKO mice ( ${ }^{* *} p<0.01$; Student's $t$ test; $n=24$ for control, $n=20$ for $\left.c K 0\right)$, but not in the nucleus accumbens core or the neostriatum. $\boldsymbol{E}$, Summary data showing the existence of a significant reduction in the number of VGLUT2-positive varicosities in the nucleus accumbens shell
TH-positive neurons was reduced by $24.4 \%$ in the VTA (control $=4362 \pm 189, \mathrm{cKO}=3297 \pm 185, p=0.002)$ and by $19.4 \%$ in the $\mathrm{SNc}$ (control $=5522 \pm 209, \mathrm{cKO}=4450 \pm 170, p=0.002$; Fig. 6A). However, no differences were observed in either the $\mathrm{SNr}$ or the RRF (Fig. $6 A$ ).

To determine whether the abnormal development of mesencephalic DA neurons in VGLUT2-deficient mice was associated with a defect in dopaminergic and/or glutamatergic innervation of the striatum, we used TH/VGLUT2 double immunohistochemistry coupled to confocal microscopy to quantify the relative number of TH, VGLUT2, and TH/VGLUT2 axon varicosities in the nucleus accumbens and neostriatum of $\mathrm{cKO}$ versus control P70 mice. A significant $33.3 \%$ decrease in the number of THpositive punctae was measured in the nucleus accumbens shell of the cKO mice $(66.7 \pm 6.7 \%$ of control, $p=0.006$; Fig. $6 B, D)$. Although this did not reach statistical significance $(p=0.08)$, a similar tendency was found in the nucleus accumbens core. Likewise, we observed a 33.6 and $38.2 \%$ decrease in the number of VGLUT2-positive axon-like varicosities in the accumbens shell $(67.4 \pm 6.3 \%$ of control, $p=0.004)$ and core $(61.8 \pm 8.7 \%$ of control, $p=0.005$ ), respectively (Fig. $6 C, E$ ). However, in the neostriatum, there were no significant differences in the number of either TH or VGLUT2 punctae (Fig. $6 B-E$ ).

Interestingly, in these double labeling experiments, we did not detect any significant colocalization of TH and VGLUT2 (Fig. $6 F, H$ ) or DAT and VGLUT2 (Fig. $6 G$ ) in axon varicosities of the ventral or dorsal striatum of Ctrl mice. The percentage of $\mathrm{TH}+$ terminals colocalizing with VGLUT2 + terminals, as detected by confocal microscopy, was relatively low in these Ctrl animals, with a value ranging from 2 to $4 \%$ in the different striatal subcompartments (data not shown). Compatible with the possibility that much of this low level of colocalization was actually false positive signal due to the dense packing of terminals in the striatum, there was no significant difference in the extent of correlation between the two signals between $\mathrm{CKO}$ and Ctrl tissue, as revealed by determination of the Pearson coefficient (Fig. $6 \mathrm{H}$ ).

The demonstration of striatal glutamate release by DA neurons in adult mice by optogenetic approaches (Stuber et al., 2010; Tecuapetla et al., 2010) combined with the present results showing there is no apparent colocalization of $\mathrm{TH}$ or DAT and VGLUT2 in axon terminals in vivo could be interpreted as suggesting the existence of segregation of glutamatergic and dopaminergic terminals established by DA neurons. To evaluate this hypothesis, we used FACS-purified DA neurons in low density standard cultures prepared from TH-GFP mice and used immunocytochemistry to examine the phenotype of axonal varicosities and axonal branches emanating from confirmed, isolated DA neurons. First, we profiled such purified 7 DIV DA neurons by

$\leftarrow$

${ }^{* *} p<0.01$; Student's $t$ test; $n=24$ for control; $n=20$ for cKO) and core $\left({ }^{* *} p<0.01\right.$; Student's $t$ test; $n=24$ for control; $n=20$ for $(K 0)$, but not in the neostriatum of cKO mice. $F$, Colocalization of TH (green) and VGLUT2 (red) immunoreactivity was examined in the nucleus accumbens shell of $\mathrm{CKO}$ mice. In the merged images on the right, note that there is minimal colocalization (yellow). The area delineated by the white square is shown at higher magnification at the extreme right. Scale bar, $40 \mu \mathrm{m}$. G, Colocalization of DAT (green) and VGLUT2 (red) immunoreactivity was also examined in the nucleus accumbens shell of $P 70 \mathrm{C} 57 \mathrm{BL} / 6 \mathrm{~J}$ mice. In the merged images on the right, note that there is again minimal colocalization (yellow) between DAT and VGLUT2. The area delineated by the white square is shown at higher magnification at the extreme right. Scale bar, $40 \mu \mathrm{m}$. $\boldsymbol{H}$, Pearson coefficient of TH and VGLUT2 immunoreactivity colocalization was not different between the genotypes ( $n=24$ for control; $n=20$ for $(K 0)$. $n$ represents the number of $50 \mu \mathrm{m}$ slices analyzed in a total of five control and four CKO P70 mice. 
B
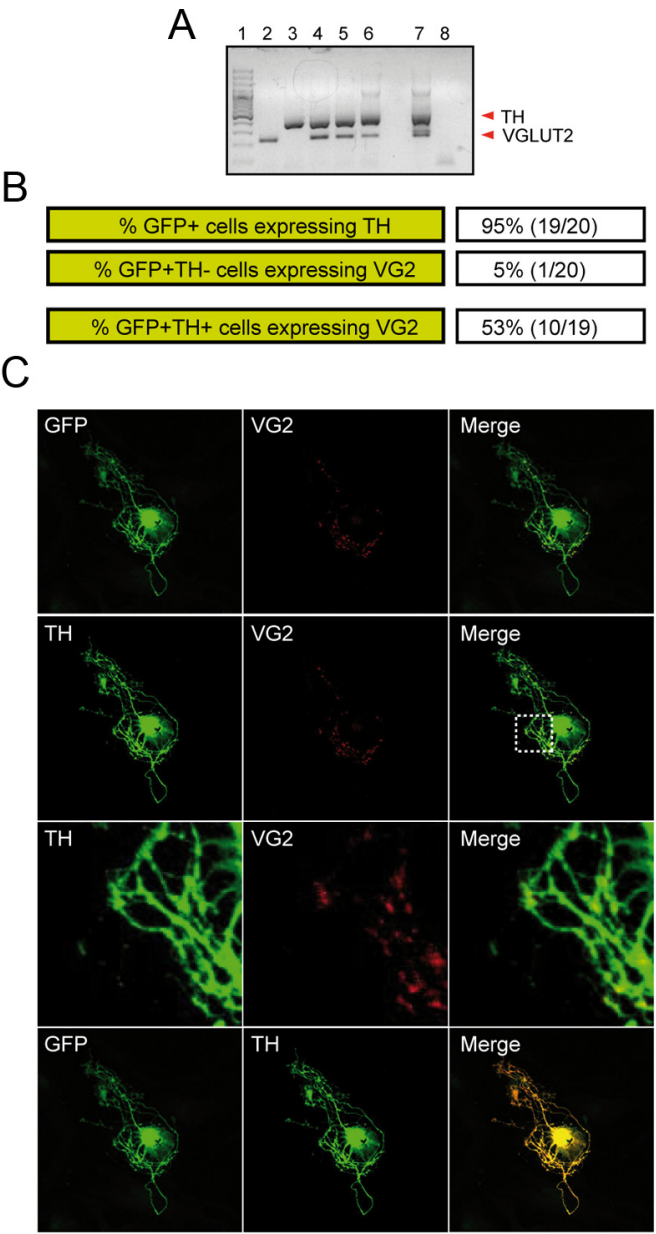

D

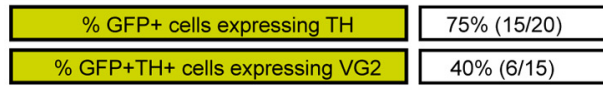

E
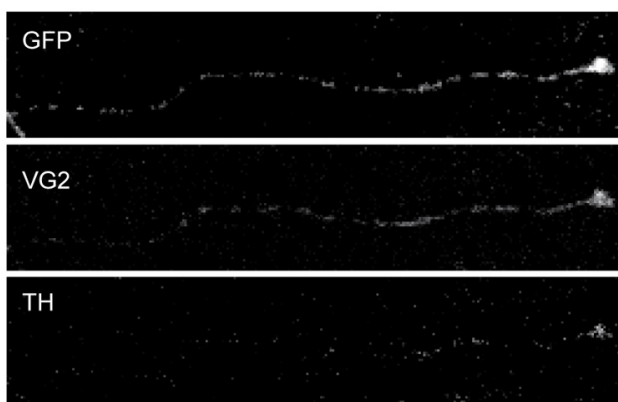

$\mathrm{F}$

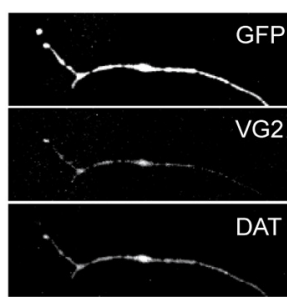

G

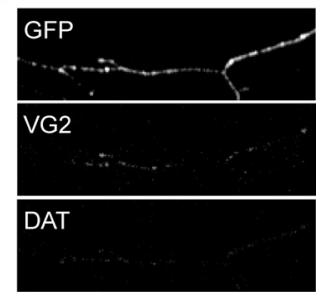

Figure 7. Colocalization of dopaminergic markers with VGLUT2 in isolated dopaminergic neurons in vitro. $\boldsymbol{A}$, Single-cell RT-PCR from 7 DIV standard FACS-purified cultured DA neurons. In this example (wells 2-6), four of the five GFP-positive neurons collected expressed Th mRNA. Well 1, DNA ladder; well 7, whole mesencephalon RNA; well 8, water control. $\boldsymbol{B}$, Table summarizing the results of single-cell RT-PCR experiments performed with a standard 7 DIV single-cell RT-PCR (Fig. 7A). We found that 95\% of the GFPpositive neurons collected contained TH mRNA and that $53 \%$ of the GFP/TH-positive neurons also contained VGLUT2 mRNA (Fig. 7B). We performed triple immunolabeling for GFP, TH, and VGLUT2 on such cultures and found that $75 \%$ of isolated GFP-positive neurons were immunolabeled by $\mathrm{TH}$; moreover, $40 \%$ of these GFP/TH-immunopositive neurons were also immunopositive for VGLUT2 (Fig. 7C,D). VGLUT2-positive axonal varicosities were found to coexpress GFP and TH in the majority of isolated DA neurons examined. However, in some cases, VGLUT2 immunoreactivity was found in a strong GFP immunolabeled axonal branch with very weak TH immunolabeling (Fig. 7E). A triple immunolabeling experiment to localize GFP, DAT, and VGLUT2 revealed similar findings, with VGLUT2-positive terminals usually showing strong GFP and DAT immunolabeling (Fig. $7 F$ ), with occasional branches showing strong GFP signal but low DAT immunolabeling (Fig. 7G). Together, these results suggest that in vitro, DA neurons can establish at least two types of glutamatergic terminals, which are either strongly or weakly immunopositive for dopaminergic markers.

\section{Reduced DA release in the nucleus accumbens of cKO mice}

The reduced density of DA innervation in the nucleus accumbens suggested that DA release might also be decreased in this part of the striatum in cKO mice. Cyclic voltammetry was therefore used to measure electrically evoked DA release in striatal brain slices prepared from male $\mathrm{P} 30 \mathrm{cKO}$ mice and their littermate controls. We compared the nucleus accumbens shell, where the most robust reduction in terminals was detected, and the neostriatum, which showed no significant change in number of axon terminals. Single pulse stimulation $(400 \mu \mathrm{A}, 1 \mathrm{~ms})$ was used to evaluate basal release, while short, physiologically relevant action potential trains $(10 \mathrm{~Hz}, 20$ pulses $)$ were used to more closely examine DA release under more demanding conditions, where D2 autoreceptors and DAT function regulate DA overflow. We found a $36.8 \%$ decrease in the amplitude of DA overflow evoked by single pulses in the nucleus accumbens shell (control $=5.7 \pm 0.4 \mathrm{nA}$, $\mathrm{cKO}=3.6 \pm 0.4 \mathrm{nA}, p=0.005$; Fig. $8 A$ ). In neostriatum, there were no significant differences between the two genotypes under these conditions (Fig. 8D). This observation confirmed previous findings (Hnasko et al., 2010). The kinetics of DA overflow (rise time and decay time) remained unchanged (Fig. $8 B-F$ ). Using action potential trains, we observed a $37.8 \%$ decrease in the maximal amount of DA overflow in the nucleus accumbens shell of $\mathrm{cKO}$ mice $($ control $=8.2 \pm 0.8 \mathrm{nA}, \mathrm{cKO}=5.1 \pm 0.7 \mathrm{nA}, p=0.03$; Fig. $8 G$ ). Here again, no significant differences were observed in the neostriatum (Fig. $8 \mathrm{~J}$ ) or in the rise time or decay time of DA overflow in either region (Fig. $8 H-L$ ). Finally, the ratio of trainevoked versus single pulse-evoked DA overflow was also unchanged in both regions (Fig. $8 M, N$ ).

The reduced number of TH-positive terminals and of DA release observed in the nucleus accumbens of $\mathrm{cKO}$ mice could also suggest a perturbation in TH activity and/or TH expression.

$\leftarrow$

FACS-purified culture. $C$, Immunofluorescence images illustrating the results of a GFP/TH/ VGLUT2 triple-immunolabeling experiment performed in an isolated DA neuron from a standard 7 DIV FACS-purified culture. D, Summary data of the immunolabeling experiments shown in $\boldsymbol{C}$, Immunofluorescence images illustrating a field from an isolated DA neuron with weak TH signal and an otherwise GFP and VGLUT2-positive axonal branch. $\boldsymbol{F}, \boldsymbol{G}$, Immunofluorescence images illustrating the results of a strong $(\boldsymbol{F})$ or weak $(\boldsymbol{G})$ DAT immunoreactivity in a GFP and VGLUT2-positive axonal branch originating from an isolated DA neuron. 
A N.Acc. shell

D Neostriatum

G

N.Acc. shell

J Neostriatum
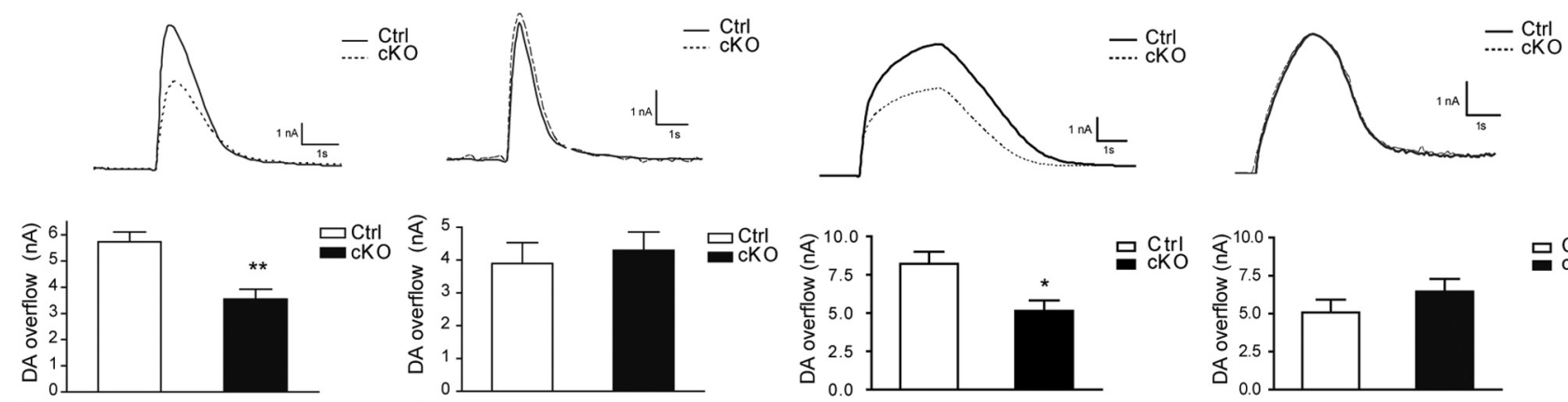

B

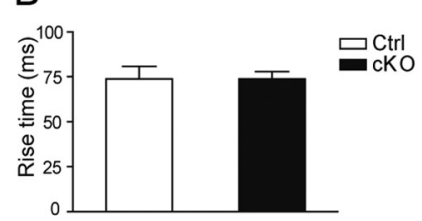

C

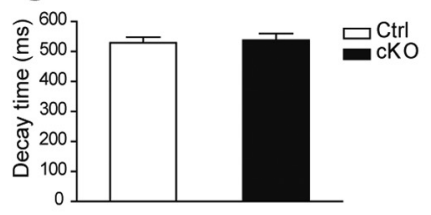

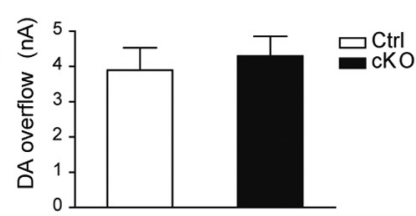

E

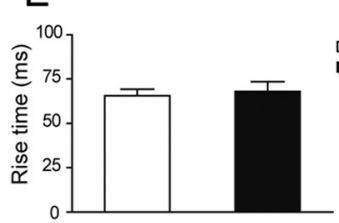

F

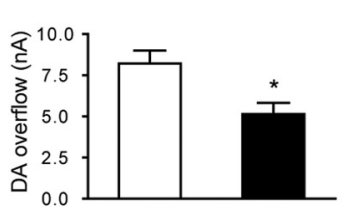

$\mathrm{H}$

므 CKO

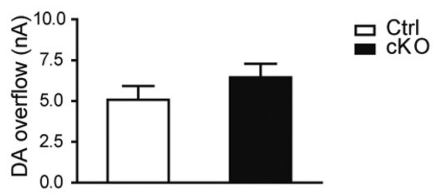

K
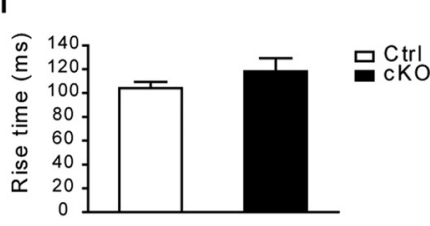

क्ष 1

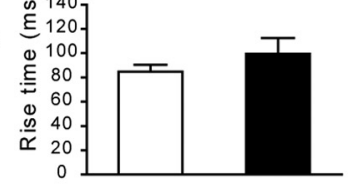

므다이

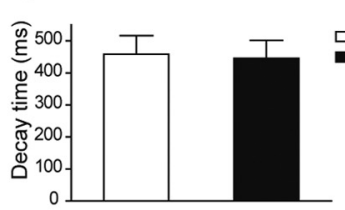

I

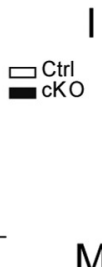

M
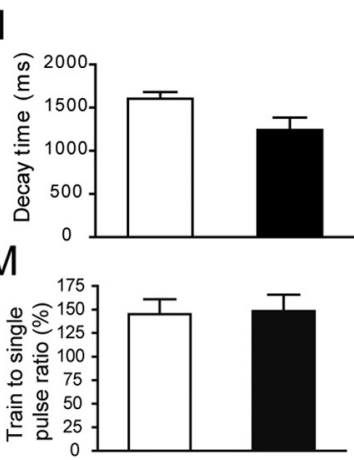

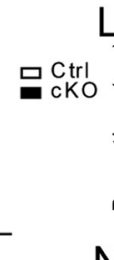

है
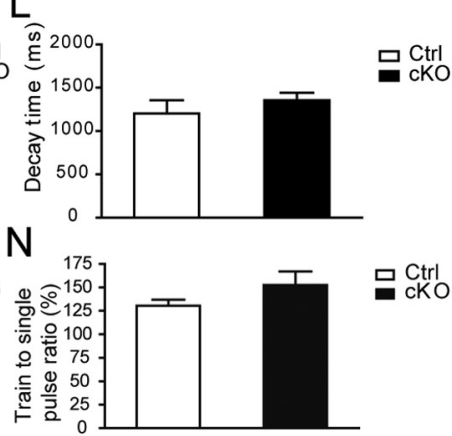

Figure 8. The magnitude but not the kinetics of DA release is decreased in the nucleus accumbens shell of conditional Vglut2 $\mathrm{KO}$ mice. A-C, Fast cyclic voltammetry recordings showing a decrease in single pulse-evoked DA overflow in the nucleus accumbens shell of P30 cKO mice ${ }^{* *} p<0.01$; Mann-Whitney rank sum test; $n=5$ for control; $n=7$ for cK0). The bar graphs illustrate average results and show that while the peak amplitude of $D A$ overflow was reduced, the rise time and decay time of the response were not altered. $\boldsymbol{D}-\boldsymbol{F}$, In the neostriatum, the amplitude and kinetics of single pulse-evoked DA overflow were not different between genotypes ( $n=6$ for control; $n=6$ for cK0). $G$, Train stimulation (20 pulses, $10 \mathrm{~Hz}$ ) was also used to evoke DA overflow. DA overflow evoked in this way was reduced (upper graph) in the nucleus accumbens (N.Acc.) shell of cKO mice $\left({ }^{*} p<0.05\right.$; Mann-Whitney rank sum test; $n=5$ for control; $n=7$ for cKO). Rise ( $\left.\boldsymbol{H}\right)$ and decay $(I)$ time of the response remained unchanged in this region. Train-evoked DA overflow $(J-L)$ was unchanged in the neostriatum $(n=6$ for control; $n=6$ for $(K 0)$. The ratio of train-evoked to single pulse-evoked DA overflow, an index of vesicle mobilization and autoreceptor control of DA release, was not changed in the nucleus accumbens shell $(\boldsymbol{M})$ or in the neostriatum $(\boldsymbol{N}) . n$ represents the total number of slices recorded in three control and three cKO P30 mice.

We performed a double-labeling experiment in mesencephalic brain sections using a $\mathrm{TH}$ antibody as well as a phospho-TH antibody. Quantification of the level of immunoreactivity allowed us to obtain an index of total $\mathrm{TH}$ as well as relative $\mathrm{TH}$ activity. First, we found that total TH immunoreactivity per neuron in the VTA and SNc was not different. Second, we found a decrease in the phospho-TH/TH ratio per DA neuron in the VTA (Fig. 9), but not in the SNc, of cKO mice. This later observation is compatible with a partial contribution of reduced $\mathrm{TH}$ activity to the reduction in DA release.

\section{cKO mice exhibit motor deficits}

The reduced DA neuron number and growth in conditional Vglut2 cKO mice raised the possibility of perturbations of DAdependent behaviors in these mice, as suggested by recent studies (Birgner et al., 2010; Hnasko et al., 2010; Alsiö et al., 2011). We examined 3- to 5-month-old male Vglut2 cKO mice and first monitored spontaneous motor activity in a novel environment. In this setting, cKO mice displayed a significant decrease of $30 \%$ in horizontal activity (total horizontal beam breaks) $(p=0.03)$ compared with littermate controls (Fig. 10A). Locomotion (sequences of $>2$ beam breaks in one direction) also showed a ten- dency toward a reduction, but this did not reach statistical significance $(p=0.11)$ (Fig. 10B). Rearing activity was not different between genotypes (Fig. 10C).

Neurotoxin-induced loss of DA neurons is known to decrease performance on the accelerating rotarod task (Rozas et al., 1998), a measure of crude motor activity and coordination. We thus examined the performance of cKO mice in this paradigm. Control and cKO mice were put on the spinning rotarod for three 1 min trials on 2 consecutive days. Compared with control, the Vglut2 cKO mice scored less for distance (Fig. 10D) on day 1 (control $=0.52 \pm 0.08 \mathrm{~m}, \mathrm{cKO}=0.31 \pm 0.07 \mathrm{~m}, p=0.018$ ), on speed (Fig. 10E) for both days (day 1: control $=19.9 \pm 1.5 \mathrm{rpm}$, $\mathrm{cKO}=15.4 \pm 1.4 \mathrm{rpm}, p=0.016$; day 2 : control $=202 \pm 2.1$ $\mathrm{rpm}, \mathrm{cKO}=15.0 \pm 1.5 \mathrm{rpm}, p=0.047)$, and on the latency to fall (Fig. 10F) for both days (day 1: control $=22.2 \pm 2.2 \mathrm{~s}, \mathrm{cKO}=$ $15.6 \pm 2.0 \mathrm{~s}, p=0.014$; day2: control $=22.7 \pm 3.2 \mathrm{~s}$, $\mathrm{cKO}=$ $15.1 \pm 2.3 \mathrm{~s}, p=0.042$ )

The cKO mice and their controls were also evaluated on the forced swim test, an index of behavioral despair. The latency to the first immobilization and the total time immobile were recorded on two consecutive trials. There was no apparent difference between genotypes in the total time spent immobile (Fig. 
A
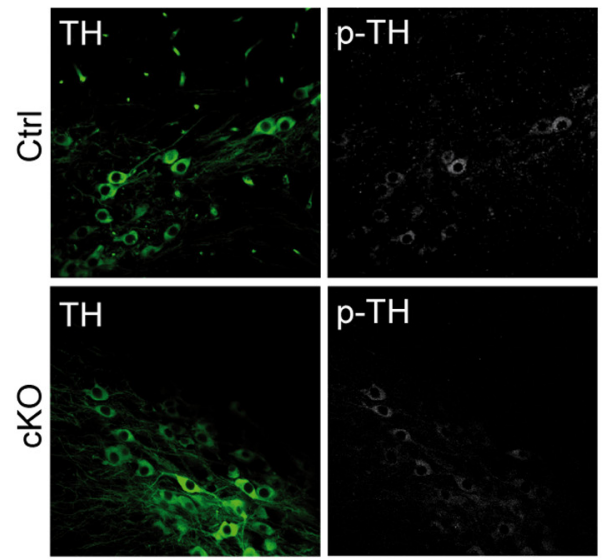

p-TH

B

$$
\text { B }
$$

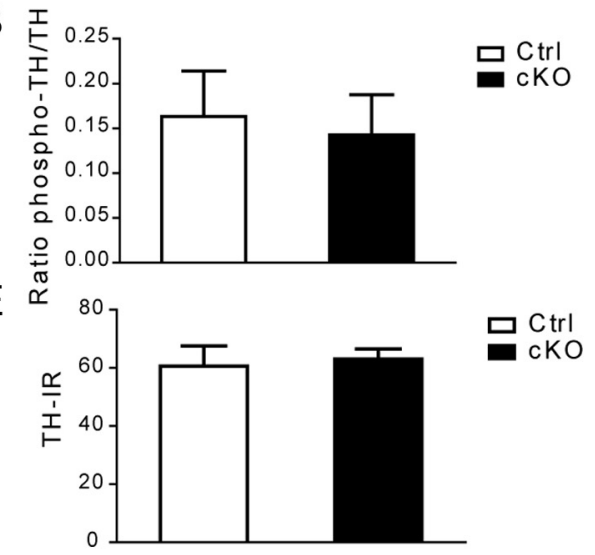

C
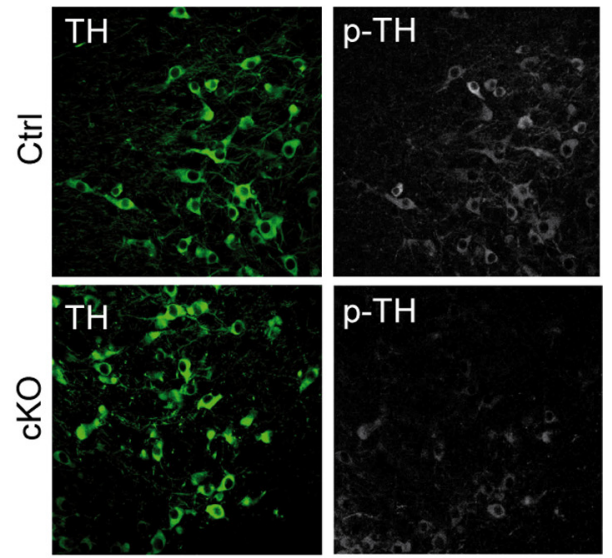

D
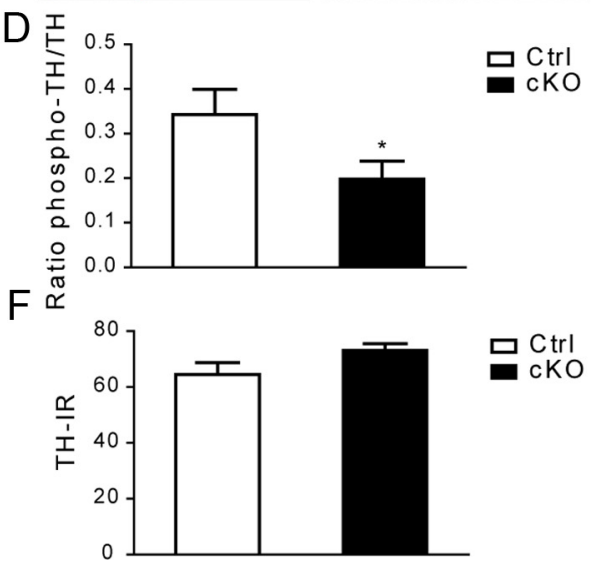

Figure 9. The ratio of p-TH/TH but not total TH is reduced in the VTA of cKO mice. $A, C$, Immunofluorescence images illustrating a TH/Ser(40)-Ph-TH double-immunolabeling experiment performed in the SNc $(\boldsymbol{A})$ or VTA ( $\boldsymbol{C}$ ) of CTRL and cKO P35 mice. $\boldsymbol{B}, \boldsymbol{D}$, The p-TH/TH ratio per TH + neuron was reduced in the VTA $(\boldsymbol{D})(p=0.047$; Mann-Whitney rank sum test; $n=12$ for control; $n=13$ for $\mathrm{CKO})$ but not in the $\mathrm{SNc}(\boldsymbol{B})(p=0.74$; Mann-Whitney rank sum test; $n=10$ for control; $n=11$ for $c K 0)$ of $c K 0$ mice. $\boldsymbol{E}$, $\boldsymbol{F}$, There was no difference in total TH immunoreactivity per dopaminergic neuron in the SNc $(\boldsymbol{E})(p=0.74$; Mann-Whitney rank sum test; $n=10$ for control; $n=11$ for $\mathrm{cK} 0)$ or the VTA $(\boldsymbol{F})(p=0.089 ;$ Mann-Whitney rank sum test; $n=12$ for control; $n=$ 13 for $\mathrm{CKO}$ ) of $\mathrm{CKO}$ mice. $n$ represents the number of slices analyzed on three animals of each genotype.

$10 G)$. However, in the first trial, the $\mathrm{CKO}$ mice showed a significant decrease in the latency to first immobilization (control = $135.4 \pm 44.2 \mathrm{~s}, \mathrm{cKO}=23.0 \pm 12.8 \mathrm{~s}, p=0.043$; Fig. $10 \mathrm{H})$.

Finally, confirming earlier results (Birgner et al., 2010; Hnasko et al., 2010), the cKO mice displayed a blunted locomotor response when challenged with amphetamine (Fig. 11A-F) or cocaine (Fig. 11G-L).

\section{Discussion}

This study suggests an important role of the glutamatergic cophenotype for the developmental regulation of the central DA system. Selective deletion of the Vglut2 gene in these neurons reduced their survival, soma size, neuritic complexity, and axonal length in culture, and entailed a reduction of their number in both the VTA and the SNc in vivo, accompanied with a selective decrease of the density of DA innervation and of DA release in the nucleus accumbens. The cKO mice also displayed motor deficits, an altered motor response to psychostimulants, and signs of behavioral despair. Altogether, these findings provide an explanation for the reduced sensitivity of such $\mathrm{cKO}$ mice to psychostimulants.

\section{Early expression of Vglut 2 in DA neurons}

In the present study, single-cell RT-PCR evidence was obtained for expression of $V g l u t 2$ mRNA by a high proportion of mesencephalic DA neurons during the late embryonic period, followed by a decrease during the postnatal period, but a return to a relatively high proportion in the adult (close to $50 \%$ at P70). The lower proportion (15\%) previously reported in P45 mice (Mendez et al., 2008) may have been due to the fact that in this earlier study, midline DA neuron cell groups, in which VGLUT2 and TH coexistence is the most frequent (Kawano et al., 2006; Yamaguchi et al., 2011), were not examined. Although the proportion of DA neurons expressing Vglut2 mRNA was higher in the VTA than SN, in young and adult mice, a subset of SN DA neurons did express Vglut2, in agreement with our previous report. It is important to consider that the relatively high proportion of DA neurons containing Vglut2 mRNA at some developmental stages does not necessarily imply that these neurons contain abundant levels of such mRNA or protein. It has recently been reported that double phenotype DA neurons express only a low copy number of Vglut2 mRNA compared with Th (Yamaguchi et al., 2011).

\section{Role for VGLUT2 in the survival and growth of} mesencephalic DA neurons

In the present study, an unbiased stereological counting method revealed a decrease of TH-positive neurons in both VTA and SNc of cKO mice. Because the level of TH immunoreactivity per neuron was found to be unchanged in either of these structures in 
cKO animals, the reduced number of $\mathrm{TH}$-positive neurons found in these mice is unlikely to be due to reduced detection of TH-positive neurons. There were also significant reductions in the number of neurons in cKO mesencephalic DA neurons cultures. Considering that $\mathrm{cKO}$ mice exhibited a $20 \%$ decrease in the total number of mesencephalic $\mathrm{TH}+$ neurons, the $23 \%$ decrease in the number of $\mathrm{TH}+$ neurons in $1 \mathrm{DIV}$ mesencephalic cKO cultures is likely due to the prior loss of DA neurons in vivo before the time of plating. Moreover, we provide pharmacological evidence suggesting that NMDA receptors contribute to the survival of these neurons in vitro. Activation of glutamate receptors may result in excitotoxicity (Choi et al., 1987), but glutamate receptor stimulation may also be neuroprotective under specific conditions (Vernon et al., 2005). One hypothesis is that glutamate release by developing DA neurons could have autocrine neurotrophic effects mediated by NMDA receptors. The recent demonstration that activation of presynaptic NMDA receptors on growth cones of DA axons facilitates neuritogenesis (Schmitz et al., 2009) combined with the results of the present study showing that early (0 -7 DIV) but not late (7-14 DIV) NMDA receptor blockade reduces survival, speaks in favor of such a model. Compatible with our model, a recent study reported attenuated phasic DA release in the nucleus accumbens following reward delivery in mice with a cKO of NR1 in DA neurons (Parker et al., 2010). Glutamate could also act through other targets such as astrocytes (Lin et al., 1993; Ho et al., 1995; Hartmann et al., 2001).

We also provide evidence for a role of the glutamatergic cophenotype in DA neuron growth. Indeed, the maturation of DA neurons cultured from Vglut $2 \mathrm{cKO}$ mice was significantly impaired, as indicated by decreased soma size, neurite complexity, and axon length. Acute application of glutamate has been shown previously to increase the rate of DA neuron axon growth (Schmitz et al., 2009). In vivo, there could be multiple sources of glutamate to regulate the growth of DA axons, but our results in vitro suggest that glutamate release by DA neurons themselves plays a significant role. An alternate explanation of the reduced survival and growth of DA neurons in $\mathrm{cKO}$ mice is that this could be due to loss of vesicular synergy between VMAT2 and VGLUT2, resulting in reduced vesicular packaging and release of DA (Hnasko et al., 2010). However, this would require that DA plays a pro-survival role in DA neurons, which is not compatible with previous work (Fasano et al., 2008a).

\section{Impaired developmental regulation of the DA system in Vglut 2 cKO mice}

Although the respective contribution of impaired survival and reduced proliferation could not be determined in the present study, we report a decrease of 25 and $20 \%$ in the number of DA neurons in the VTA and SNc, respectively, in cKO mice. We also found a decrease in the ratio of phospho- to total $\mathrm{TH}$, an index of the relative state of phosphorylation of $\mathrm{TH}$ and of $\mathrm{TH}$ activity, in VTA DA neurons. This later observation stands in contrast to findings reported in another study (Hnasko et al., 2010). The $30 \%$ decrease in density of DA innervation, associated with a $40 \%$ decrease in the amount of electrically evoked DA release in the nucleus accumbens of the cKO mice, was consistent with the DA cell loss in the VTA. Reduced TH activity could also have contributed in part to the observed decrease in DA release. A comparable decrease in DA release has been previously reported in the nucleus accumbens of such cKO mice (Hnasko et al., 2010). In the absence of differences in the kinetics of DA overflow or in the ratio of train-evoked versus single pulse-evoked DA overflow in cKO mice, major changes in DA reuptake, vesicle mobilization, and/or DA autoreceptor feedback regulation seem unlikely (Benoit-Marand et al., 2001).

Loss of vesicular synergy between VMAT2 and VGLUT2, resulting in reduced vesicular packaging and release of DA (Hnasko et al., 2010), could represent an alternate explanation for the decreased release of DA in the nucleus accumbens of cKO mice. The almost complete absence of colocalization of $\mathrm{TH}$ and VGLUT2 in dual labeling immunofluorescence and in immunoelectron microscopy experiments (Bérubé-Carrière et al., 2012) does not provide strong support for the vesicular synergy hypothesis; however, these findings highlight an intriguing biological phenomenon. Our in vitro results revealing the existence of dopaminergic axonal branches with very weak TH or DAT immunoreactivity raise the hypothesis that VGLUT2-positive terminals established by DA neurons in the striatum in vivo express only low levels of $\mathrm{TH}$, thus making them difficult to detect using standard immunohistochemical techniques. It is important to highlight the fact that immunolabeling ap- 

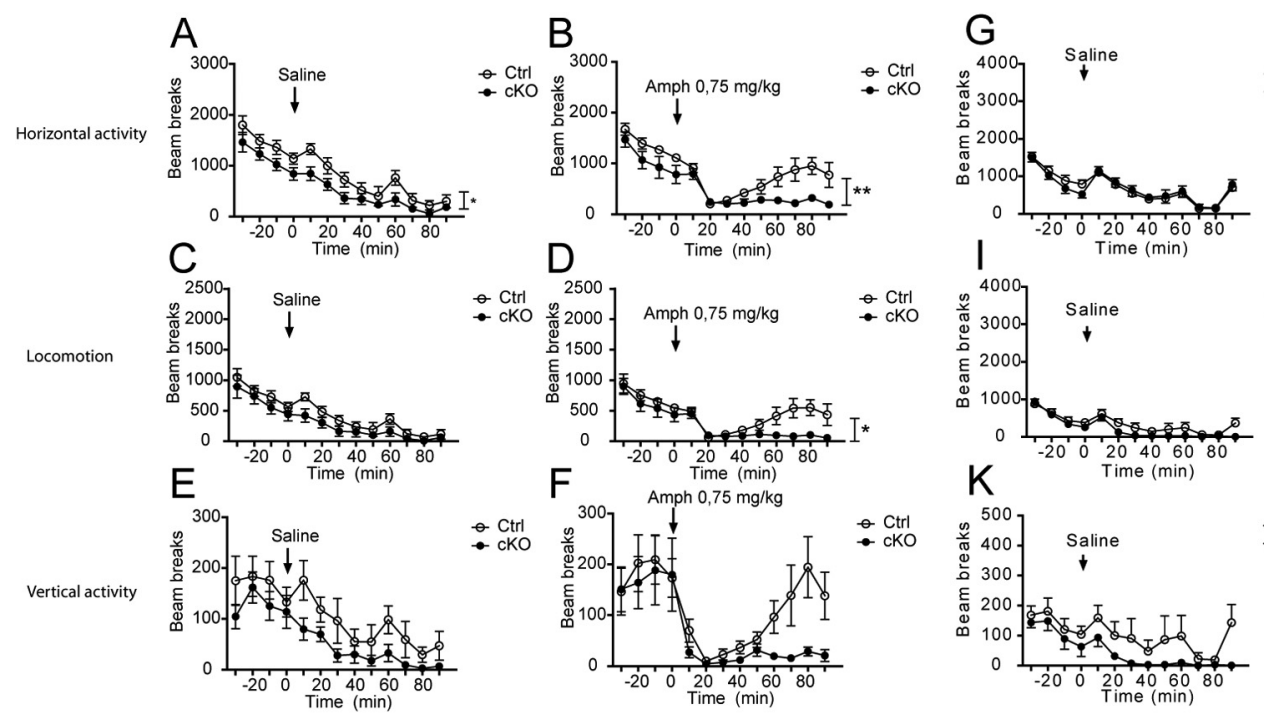

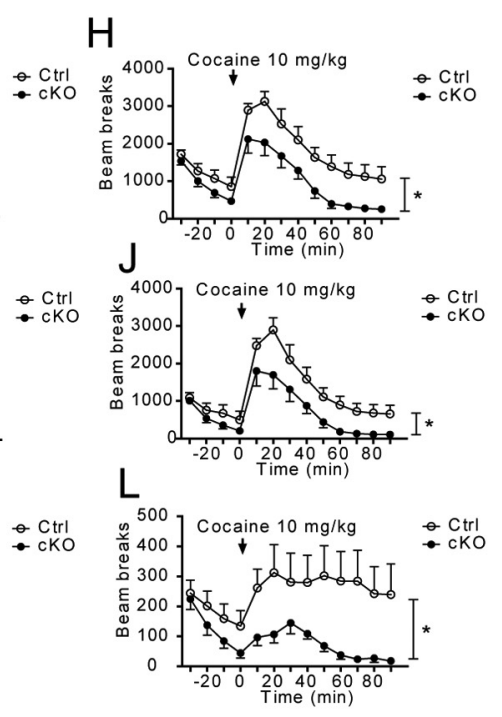

Figure 11. Blunted locomotor response to amphetamine and cocaine. cK0 mice displayed a decreased horizontal activity $(\boldsymbol{A}, \boldsymbol{B})$ and locomotion $(\boldsymbol{C}, \boldsymbol{D})$, but no difference in vertical activity $(\boldsymbol{E}, \boldsymbol{F})$ when challenged by $0.75 \mathrm{mg} / \mathrm{kg}$ amphetamine $\left({ }^{*} p<0.05 ;{ }^{* *} p<0.01\right.$; two-way ANOVA test; $n=7$ for control; $n=12$ for $\left.\mathrm{CKO}\right)$. cKO mice also displayed decreased horizontal activity $(\mathbf{G}, \boldsymbol{H})$, locomotion $(I, J)$, and vertical activity $(\boldsymbol{K}, \boldsymbol{L})$ when challenged by $10 \mathrm{mg} / \mathrm{kg}$ cocaine $\left({ }^{*} p<0.05\right.$; two-way ANOVA test; $n=7$ for control; $n=12$ for cKO). $n$ represents the number of 3 - to 5 -month-old control or cKO mice.

proaches simply cannot distinguish between complete lack of expression and low, subdetection, levels of proteins in specific cellular compartments.

Why the reduced number of SNc DA neurons did not lead to significant reductions in the number of axon varicosities and DA release in the neostriatum of Vglut $2 \mathrm{cKO}$ mice remains to be explained. Compensatory sprouting may have occurred, as seen in Parkinson's disease or in response to partial 6-OHDA lesions (Rosenblad et al., 1998; Lee et al., 2008). An alternate possibility is that the $\mathrm{SNc}$ neurons that were lost in the Vglut2 cKO mice are part of the small contingent of SNc neurons that preferentially innervate the nucleus accumbens (Lynd-Balta and Haber, 1994; Prensa and Parent, 2001). It may also be that the stimuli used to trigger DA release in the present experiments did not sufficiently challenge DA pools in nigrostriatal terminals. Compatible with this possibility, evidence has been provided recently for reduced DA release in the dorsolateral striatum of $\mathrm{Vglut} 2 \mathrm{cKO}$ in response to potassium depolarization (Alsiö et al., 2011).

As for the 35\% decrease in the number of VGLUT2-positive axon terminals in the nucleus accumbens shell and core, it could account for the recent finding of a tendency toward a decrease in potassium-evoked glutamate release in the nucleus accumbens core of another conditional Vglut2 cKO mice (Birgner et al., 2010). This reduced number of VGLUT2-positive axon terminals might reflect the absence of glutamatergic terminals established by DA neurons projecting to the nucleus accumbens, or represent an indirect effect.

\section{Evidence for a role of the glutamate cophenotype in motor function}

The behavioral profile of two different lines of conditional Vglut2 cKO mice has been recently examined in two studies; interestingly, both of these groups reported reduced behavioral activation in response to amphetamine and cocaine (Birgner et al., 2010; Hnasko et al., 2010). The present report confirms these results, but also provides evidence supporting motor impairment in the $\mathrm{cKO}$ mice, including reduced per- formance in the rotarod task. A similar deficit in the rotarod test was not found in the other reports (Birgner et al., 2010; Hnasko et al., 2010). The reason for this discrepancy is unclear, but sex differences could be involved because only males were used in the present work, while both males and females were used in the other studies (Birgner et al., 2010; Hnasko et al., 2010). As no changes were observed in DA release (Alsiö et al., 2011) and in the density of dopaminergic terminals in the neostriatum, reduced performance in the rotarod task could be due to reduced somatodendritic DA release in the SNc (Andersson et al., 2006), resulting from the decreased number of DA neurons in this nucleus. Reduced somatodendritic DA release could also contribute to the impaired response to psychostimulants in these cKO mice. A contribution of reduced striatal glutamatergic drive to these behavioral impairments is also likely. Our finding of reduced performance in the forced swim test could reflect depressive behavior or behavioral despair in the cKO mice, due to perturbed interactions between DA and 5-HT neurons (Wong et al., 1995). An alternate explanation might be altered motivation, consistent with a role of the glutamatergic cophenotype of DA neurons in reward and motivated behaviors, as suggested by recent work demonstrating altered self-administration of high-sucrose food and cocaine in Vglut2 cKO mice (Alsiö et al., 2011).

In summary, the present report suggests an important role for the glutamatergic cophenotype of DA neurons in the development and the regulation of the mesostriatal dopaminergic system. Considering the involvement of this system in a number of serious diseases such as Parkinson's, schizophrenia, and drug dependence, it opens new perspectives into the underlying pathophysiological processes of such disorders.

\section{References}

Alsiö J, Nordenankar K, Arvidsson E, Birgner C, Mahmoudi S, Halbout B, Smith C, Fortin GM, Olson L, Descarries L, Trudeau LE, Kullander K, Lévesque D, Wallén-Mackenzie A (2011) Enhanced sucrose and cocaine self-administration and cue-induced drug seeking after loss of 
VGLUT2 in midbrain dopamine neurons in mice. J Neurosci 31: 12593-12603. CrossRef Medline

Andersson DR, Nissbrandt H, Bergquist F (2006) Partial depletion of dopamine in substantia nigra impairs motor performance without altering striatal dopamine neurotransmission. Eur J Neurosci 24:617-624. CrossRef Medline

Bellocchio EE, Reimer RJ, Fremeau RT Jr, Edwards RH (2000) Uptake of glutamate into synaptic vesicles by an inorganic phosphate transporter. Science 289:957-960. CrossRef Medline

Benoit-Marand M, Borrelli E, Gonon F (2001) Inhibition of dopamine release via presynaptic D2 receptors: time course and functional characteristics in vivo. J Neurosci 21:9134-9141. Medline

Bérubé-Carrière N, Riad M, Dal Bo G, Lévesque D, Trudeau LE, Descarries L (2009) The dual dopamine-glutamate phenotype of growing mesencephalic neurons regresses in mature rat brain. J Comp Neurol 517:873891. CrossRef Medline

Bérubé-Carrière N, Guay G, Fortin GM, Kullander K, Olson L, WallénMackenzie Å, Trudeau LE, Descarries L (2012) Ultrastructural characterization of the mesostriatal dopamine innervation in mice, including two mouse lines of conditional Vglut2 knockout in dopamine neurons. Eur J Neurosci 35:527-538. CrossRef Medline

Birgner C, Nordenankar K, Lundblad M, Mendez JA, Smith C, le Grevès M, Galter D, Olson L, Fredriksson A, Trudeau LE, Kullander K, WallénMackenzie A (2010) VGLUT2 in dopamine neurons is required for psychostimulant-induced behavioral activation. Proc Natl Acad Sci U S A 107:389-394. CrossRef Medline

Bourque MJ, Trudeau LE (2000) GDNF enhances the synaptic efficacy of dopaminergic neurons in culture. Eur J Neurosci 12:3172-3180. CrossRef Medline

Choi DW, Maulucci-Gedde M, Kriegstein AR (1987) Glutamate neurotoxicity in cortical cell culture. J Neurosci 7:357-368. Medline

Dal Bo G, St-Gelais F, Danik M, Williams S, Cotton M, Trudeau LE (2004) Dopamine neurons in culture express VGLUT2 explaining their capacity to release glutamate at synapses in addition to dopamine. J Neurochem $1398-1405$.

Dal Bo G, Bérubé-Carrière N, Mendez JA, Leo D, Riad M, Descarries L, Lévesque D, Trudeau LE (2008) Enhanced glutamatergic phenotype of mesencephalic dopamine neurons after neonatal 6-hydroxydopamine lesion. Neuroscience 156:59-70. CrossRef Medline

Descarries L, Bérubé-Carrière N, Riad M, Dal Bo GD, Mendez JA, Trudeau LE (2008) Glutamate in dopamine neurons: synaptic versus diffuse transmission. Brain Res Rev 58:290-302. CrossRef Medline

Dobi A, Margolis EB, Wang HL, Harvey BK, Morales M (2010) Glutamatergic and nonglutamatergic neurons of the ventral tegmental area establish local synaptic contacts with dopaminergic and nondopaminergic neurons. J Neurosci 30:218-229. CrossRef Medline

El Mestikawy S, Wallén-Mackenzie A, Fortin GM, Descarries L, Trudeau LE (2011) From glutamate co-release to vesicular synergy: vesicular glutamate transporters. Nat Rev Neurosci 12:204-216. CrossRef Medline

Fasano C, Poirier A, DesGroseillers L, Trudeau LE (2008a) Chronic activation of the D2 dopamine autoreceptor inhibits synaptogenesis in mesencephalic dopaminergic neurons in vitro. Eur J Neurosci 28: 1480-1490. CrossRef Medline

Fasano C, Thibault D, Trudeau LE (2008b) Culture of postnatal mesencephalic dopamine neurons on an astrocyte monolayer. Curr Protoc Neurosci Chapter 3:Unit 3.21. Medline

Fasano C, Kortleven C, Trudeau LE (2010) Chronic activation of the D2 autoreceptor inhibits both glutamate and dopamine synapse formation and alters the intrinsic properties of mesencephalic dopamine neurons in vitro. Eur J Neurosci 32:1433-1441. CrossRef Medline

Gras C, Amilhon B, Lepicard EM, Poirel O, Vinatier J, Herbin M, Dumas S, Tzavara ET, Wade MR, Nomikos GG, Hanoun N, Saurini F, Kemel ML, Gasnier B, Giros B, El Mestikawy S (2008) The vesicular glutamate transporter VGLUT3 synergizes striatal acetylcholine tone. Nat Neurosci 11:292-300. CrossRef Medline

Hartmann M, Heumann R, Lessmann V (2001) Synaptic secretion of BDNF after high-frequency stimulation of glutamatergic synapses. EMBO J 20: 5887-5897. CrossRef Medline

Herzog E, Bellenchi GC, Gras C, Bernard V, Ravassard P, Bedet C, Gasnier B, Giros B, El Mestikawy S (2001) The existence of a second vesicular glutamate transporter specifies subpopulations of glutamatergic neurons. J Neurosci 21:RC181. Medline
Hnasko TS, Chuhma N, Zhang H, Goh GY, Sulzer D, Palmiter RD, Rayport S, Edwards RH (2010) Vesicular glutamate transport promotes dopamine storage and glutamate corelease in vivo. Neuron 65:643-656. CrossRef Medline

Ho A, Gore AC, Weickert CS, Blum M (1995) Glutamate regulation of GDNF gene expression in the striatum and primary striatal astrocytes. Neuroreport 6:1454-1458. CrossRef Medline

Kawagoe KT, Zimmerman JB, Wightman RM (1993) Principles of voltammetry and microelectrode surface states. J Neurosci Methods 48: 225-240. CrossRef Medline

Kawano M, Kawasaki A, Sakata-Haga H, Fukui Y, Kawano H, Nogami H, Hisano S (2006) Particular subpopulations of midbrain and hypothalamic dopamine neurons express vesicular glutamate transporter 2 in the rat brain. J Comp Neurol 498:581-592. CrossRef Medline

Lee J, Zhu WM, Stanic D, Finkelstein DI, Horne MH, Henderson J, Lawrence AJ, O'Connor L, Tomas D, Drago J, Horne MK (2008) Sprouting of dopamine terminals and altered dopamine release and uptake in Parkinsonian dyskinaesia. Brain 131:1574-1587. CrossRef Medline

Lin LF, Doherty DH, Lile JD, Bektesh S, Collins F (1993) GDNF: a glial cell line-derived neurotrophic factor for midbrain dopaminergic neurons. Science 260:1130-1132. CrossRef Medline

Lynd-Balta E, Haber SN (1994) The organization of midbrain projections to the striatum in the primate: sensorimotor-related striatum versus ventral striatum. Neuroscience 59:625-640. CrossRef Medline

Manders EMM, Verbeek FJ, Aten JA (1993) Measurement of co-localisation of objects in dual-colour confocal images. J Microsc 169:375-382. CrossRef

Matsushita N, Okada H, Yasoshima Y, Takahashi K, Kiuchi K, Kobayashi K (2002) Dynamics of tyrosine hydroxylase promoter activity during midbrain dopaminergic neuron development. J Neurochem 82:295304. CrossRef Medline

Meijering E, Jacob M, Sarria JC, Steiner P, Hirling H, Unser M (2004) Design and validation of a tool for neurite tracing and analysis in fluorescence microscopy images. Cytometry A 58:167-176. CrossRef

Mendez JA, Bourque MJ, Dal Bo G, Bourdeau ML, Danik M, Williams S, Lacaille JC, Trudeau LE (2008) Developmental and target-dependent regulation of vesicular glutamate transporter expression by dopamine neurons. J Neurosci 28:6309-6318. CrossRef Medline

Parker JG, Zweifel LS, Clark JJ, Evans SB, Phillips PE, Palmiter RD (2010) Absence of NMDA receptors in dopamine neurons attenuates dopamine release but not conditioned approach during Pavlovian conditioning. Proc Natl Acad Sci U S A 107:13491-13496. CrossRef Medline

Paxinos G, Franklin KBJ (2008) The mouse brain in stereotaxic coordinates, Compact third edition: the coronal plates and diagrams. Amsterdam: Elsevier.

Porsolt RD, Le Pichon M, Jalfre M (1977) Depression: a new animal model sensitive to antidepressants treatments. Nature 266:730-732. CrossRef Medline

Prensa L, Parent A (2001) The nigrostriatal pathway in the rat: a singleaxon study of the relationship between dorsal and ventral tier nigral neurons and the striosome/matrix striatal compartments. J Neurosci 21:7247-7260. Medline

Rosenblad C, Martinez-Serrano A, Björklund A (1998) Intrastriatal glial cell line-derived neurotrophic factor promotes sprouting of spared nigrostriatal dopaminergic afferents and induces recovery of function in a rat model of Parkinson's disease. Neuroscience 82:129-137. CrossRef Medline

Rozas G, López-Martín E, Guerra MJ, Labandeira-García JL (1998) The overall rod performance test in the MPTP-treated-mouse model of Parkinsonism. J Neurosci Methods 83:165-175. CrossRef Medline

Schmitz Y, Luccarelli J, Kim M, Wang M, Sulzer D (2009) Glutamate controls growth rate and branching of dopaminergic axons. J Neurosci 29: 11973-11981. CrossRef Medline

Stuber GD, Hnasko TS, Britt JP, Edwards RH, Bonci A (2010) Dopaminergic terminals in the nucleus accumbens but not the dorsal striatum corelease glutamate. J Neurosci 30:8229-8233. CrossRef Medline

Sulzer D, Joyce MP, Lin L, Geldwert D, Haber SN, Hattori T, Rayport S (1998) Dopamine neurons make glutamatergic synapses in vitro. J Neurosci 18:4588-4602. Medline

Takamori S, Rhee JS, Rosenmund C, Jahn R (2000) Identification of a vesicular glutamate transporter that defines a glutamatergic phenotype in neurons. Nature 407:189-194. CrossRef Medline 
Takamori S, Rhee JS, Rosenmund C, Jahn R (2001) Identification of differentiation-associated brain-specific phosphate transporter as a second vesicular glutamate transporter (VGLUT2). J Neurosci 21:RC182. Medline

Tecuapetla F, Patel JC, Xenias H, English D, Tadros I, Shah F, Berlin J, Deisseroth K, Rice ME, Tepper JM, Koos T (2010) Glutamatergic signaling by mesolimbic dopamine neurons in the nucleus accumbens. J Neurosci 30:7105-7110. CrossRef Medline

Tong Q, Ye C, McCrimmon RJ, Dhillon H, Choi B, Kramer MD, Yu J, Yang Z, Christiansen LM, Lee CE, Choi CS, Zigman JM, Shulman GI, Sherwin RS, Elmquist JK, Lowell BB (2007) Synaptic glutamate release by ventromedial hypothalamic neurons is part of the neurocircuitry that prevents hypoglycemia. Cell Metabolism 5:383-393. CrossRef Medline

van den Munckhof P, Luk KC, Ste-Marie L, Montgomery J, Blanchet PJ, Sadikot AF, Drouin J (2003) Pitx3 is required for motor activity and for survival of a subset of midbrain dopaminergic neurons. Development 130:2535-2542. CrossRef Medline
Vernon AC, Palmer S, Datla KP, Zbarsky V, Croucher MJ, Dexter DT (2005) Neuroprotective effects of metabotropic glutamate receptor ligands in a 6-hydroxydopamine rodent model of Parkinson's disease. Eur J Neurosci 22:1799-1806. CrossRef Medline

Wong PT, Feng H, Teo WL (1995) Interaction of the dopaminergic and serotonergic systems in the rat striatum: effects of selective antagonists and uptake inhibitors. Neurosci Res 23:115-119. CrossRef Medline

Yamaguchi T, Sheen W, Morales M (2007) Glutamatergic neurons are present in the rat ventral tegmental area. Eur J Neurosci 25:106-118. CrossRef Medline

Yamaguchi T, Wang HL, Li X, Ng TH, Morales M (2011) Mesocorticolimbic glutamatergic pathway. J Neurosci 31:8476-8490. CrossRef Medline

Zhuang X, Masson J, Gingrich JA, Rayport S, Hen R (2005) Targeted gene expression in dopamine and serotonin neurons of the mouse brain. J Neurosci Methods 143:27-32. CrossRef Medline 